Article

\title{
Impact of Climate Change on Precipitation Extremes over Ho Chi Minh City, Vietnam
}

\author{
Dao Nguyen Khoi ${ }^{1,2}$, Nguyen Trong Quan ${ }^{2}\left(\mathbb{D}\right.$, Pham Thi Thao Nhi ${ }^{2}$ and Van Thinh Nguyen ${ }^{3, *}$ \\ 1 Faculty of Environment, University of Science, Vietnam National University Ho Chi Minh City, \\ Ho Chi Minh City 700000, Vietnam; dnkhoi@hcmus.edu.vn \\ 2 Institute for Computational Science and Technology, Ho Chi Minh City 700000, Vietnam; \\ quannguyen201294@gmail.com (N.T.Q.); nhi.ptt@icst.org.vn (P.T.T.N.) \\ 3 Department of Civil and Environmental Engineering, Seoul National University, 1 Gwanak-ro, Gwanak-gu, \\ Seoul 151-744, Korea \\ * Correspondence: vnguyen@snu.ac.kr; Tel.: +82-2-880-7355
}

check for updates

Citation: Khoi, D.N.; Trong Quan, N.; Thi Thao Nhi, P.; Nguyen, V.T. Impact of Climate Change on Precipitation Extremes over Ho Chi Minh City, Vietnam. Water 2021, 13, 120. https:/ / doi.org/10.3390/w13020120

Received: 24 November 2020

Accepted: 4 January 2021

Published: 7 January 2021

Publisher's Note: MDPI stays neutral with regard to jurisdictional clai$\mathrm{ms}$ in published maps and institutional affiliations.

Copyright: $\odot 2021$ by the authors. Licensee MDPI, Basel, Switzerland. This article is an open access article distributed under the terms and conditions of the Creative Commons Attribution (CC BY) license (https:// creativecommons.org/licenses/by/ $4.0 /)$.

\begin{abstract}
In the context of climate change, the impact of hydro-meteorological extremes, such as floods and droughts, has become one of the most severe issues for the governors of mega-cities. The main purpose of this study is to assess the spatiotemporal changes in extreme precipitation indices over Ho Chi Minh City, Vietnam, between the near (2021-2050) and intermediate (2051-2080) future periods with respect to the baseline period (1980-2009). The historical extreme indices were calculated through observed daily rainfall data at 11 selected meteorological stations across the study area. The future extreme indices were projected based on a stochastic weather generator, the Long Ashton Research Station Weather Generator (LARS-WG), which incorporates climate projections from the Coupled Model Intercomparison Project 5 (CMIP5) ensemble. Eight extreme precipitation indices, such as the consecutive dry days (CDDs), consecutive wet days (CWDs), number of very heavy precipitation days (R20mm), number of extremely heavy precipitation days (R25mm), maximum $1 \mathrm{~d}$ precipitation amount (RX1day), maximum $5 \mathrm{~d}$ precipitation amount ( $\mathrm{RX} 5$ day), very wet days (R95p), and simple daily intensity index (SDII) were selected to evaluate the multi-model ensemble mean changes of extreme indices in terms of intensity, duration, and frequency. The statistical significance, stability, and averaged magnitude of trends in these changes, thereby, were computed by the Mann-Kendall statistical techniques and Sen's estimator, and applied to each extreme index. The results indicated a general increasing trend in most extreme indices for the future periods. In comparison with the near future period (2021-2050), the extreme intensity and frequency indices in the intermediate future period (2051-2080) present more statistically significant trends and higher growing rates. Furthermore, an increase in most extreme indices mainly occurs in some parts of the central and southern regions, while a decrease in those indices is often projected in the north of the study area.
\end{abstract}

Keywords: extreme precipitation; LARS-WG; CMIP5; spatiotemporal changes; climate change

\section{Introduction}

According to the Global Risks Report 2019 published by the World Economic Forum (WEF), extreme weather events (e.g., heavy rainfall or heat waves) and the failure of climate-change mitigation and adaptation have remained as the top three risks in terms of likelihood and impact on the environment and human being [1]. In addition, the Intergovernmental Panel on Climate Change (IPCC) states in their Fifth Assessment Report (AR5) that the global average surface temperature is expected to rise, and precipitation is likely to occur more intensely and frequently in the 21 st century [2,3]. In other words, as a result of greenhouse gas emissions (GHGs), the evidence has shown that a growing shift of temperature and humidity at global near-surface and troposphere layer could be potential for precipitation changes in the frequency, intensity, and duration of extreme 
events around the world [4-6]. It should be noticed that extreme climate events have always posed ever-intensifying threats to most aspects of natural resources and daily life, such as natural ecosystems and biodiversity [7-9]; human life, community health and social care systems [10,11]; energy supply and demand, transportation, and urbanization [12-14]; economics and agricultural productions [15-17], etc. Therefore, the study on extreme climate events has been of great concern to the scientific community and governments around the globe for planning and implementing efficient mitigation and adaptation strategies.

To identify and examine the extreme events and their variation in the context of climate change, quantitative approaches for evaluating the extreme climatic indices have been developed and widely used by various researchers [18-20]. For consolidating the definition of climate extreme indices on a global scale, as well as facilitating research to compare differences in climate extremes across different study areas, a set of 27 extreme climatic indices computed from daily temperature and precipitation data series has been proposed and highly recommended by the Expert Team on Climate Change Detection and Indices [21]. Afterward, there is a large volume of publications using these proposed indices to address the concerned issues on the analysis of climate extremes in the context of climate change [22,23]. Particularly, in the study of Tian et al. [24], trend analysis of temporal and spatial variability of extreme precipitation indices has attracted more attention. Therefore, this study is focused on assessment of the spatiotemporal variation of extreme precipitation over Ho Chi Minh City caused by climate change. The future climate change scenarios are usually produced using two downscaling techniques based on the outputs of general circulation models (GCMs), namely, statistical downscaling technique and dynamical downscaling technique. In comparison to the dynamical downscaling technique, the statistical downscaling technique is simple to apply to different regions at the station scale and requires fewer computing resources [25]. In this study, the well-known stochastic weather generator, LARS-WG, which incorporates climate projections from the Coupled Model Intercomparison Project 5 [26] ensemble, was used. Instead of analyzing by individual model, a methodology of multi-model ensemble mean is applied to compute future precipitation data for the assessment of the impact of climate change.

Ho Chi Minh City (HCMC) is the largest economic and financial center of Vietnam. Although the City occupies just $0.6 \%$ of the country's area and contains a total population of around 8.8 million inhabitants in 2018 (approximately $8.34 \%$ of the population of Vietnam), it occupies about 23\% GDP of Vietnam (2019). Besides its rapid economic growth, HCMC has been encountering many challenges, varying from natural extreme weather to anthropogenic impacts. Additionally, HCMC has been ranked in the top 20 coastal cities that is considered to be vulnerable and severely affected by climate change, and the estimated cost for mitigation and adaptation of climate change impacts is expected to be the highest in the East Asia region [27,28]. Furthermore, according to the projected scenarios of Asian Development Bank (ADB), over $61 \%$ of the city area will be covered by regular flooding, and HCMC will be entirely submerged under water due to sea level rise by 2050 [29]. Therefore, given the high extra cost linked to climate change, it is profoundly essential to consider the potential climate-related risks as an integral part of urban management and planning [30]; particularly, a localized case study is highly recommended for the analysis of changes in extreme precipitation events [31-33].

Eventually, the aim of this study is (1) to compute and evaluate the spatial and temporal trends in extreme precipitation indices over HCMC in the future period (20212080); (2) to assess the spatiotemporal changes of trends in those extreme indices with the effect of climate change. An expectation of this study is to obtain informative assessment of the spatial and temporal variability of extreme precipitation events in HCMC during the current and future periods, in order to contribute scientific references to the governors for planning strategies to integrate climate change mitigation and adaptation frameworks for the city development. 


\section{Study Area and Data Preparation}

\subsection{Study Area}

Located in the south of Vietnam, HCMC (Figure 1) has been recognized as an extraordinarily economic and financial center in Vietnam, and also a vibrant metropolis with the rapid industrialization, urbanization, and agricultural intensification. The climate in HCMC is identified as the tropical monsoon regime with specificity of two distinguished seasons, rainy and dry. In the dry season from November to April, the city obtains a low rainfall (approximately of $10-15 \%$ of the total annual rainfall), high evaporation, and high temperature (around $29-30^{\circ} \mathrm{C}$ ). On the other hand, the average rainfall during the rainy season from May to October generally accounts for approximately $85-90 \%$ of the total annual rainfall, which has approximately varied from 1000 to $1600 \mathrm{~mm}$ in recent years as shown in Figure 2.

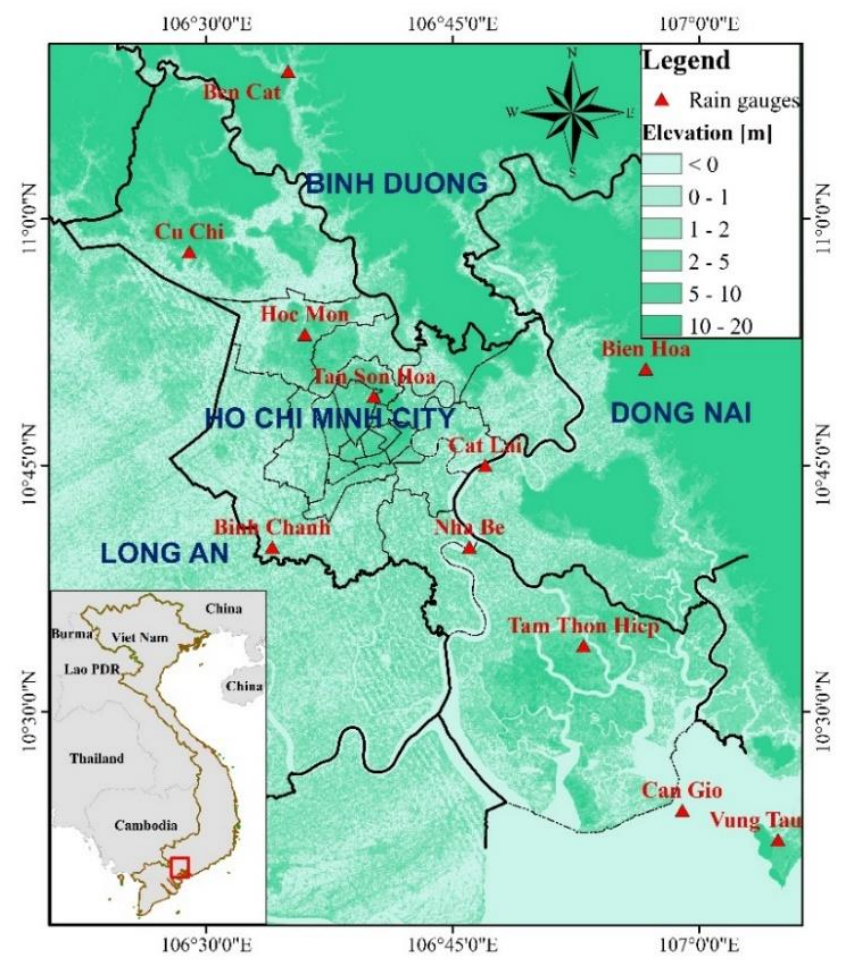

Figure 1. Map of Ho Chi Minh City and the location of 11 meteorological stations.

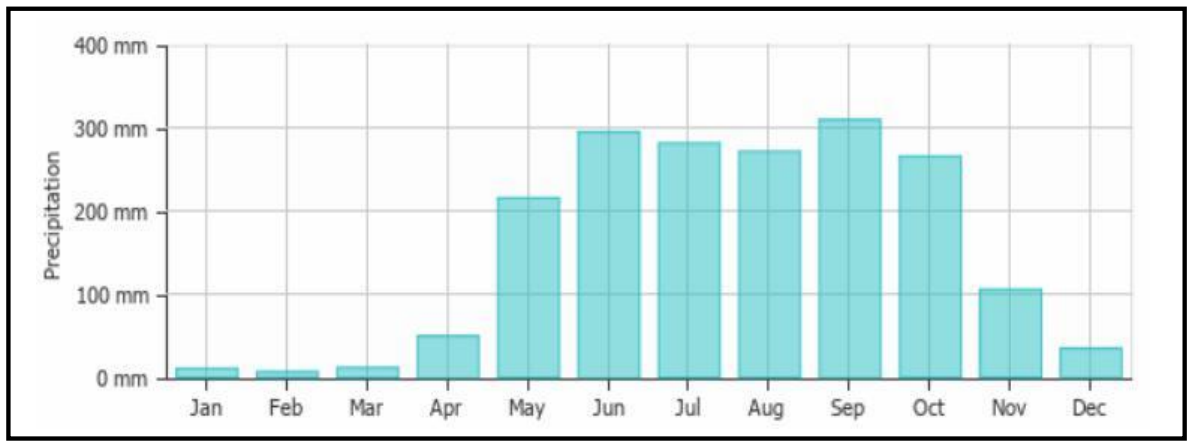

Figure 2. Average monthly precipitation in Ho Chi Minh City, Vietnam (source: weather-andclimate.com).

With an area of $2095 \mathrm{~km}^{2}$, HCMC is located on the delta formed by the Saigon and Dong Nai Rivers. Its topography is mostly plain, including small hills; approximately $50 \%$ of its elevation is lower than $1.5 \mathrm{~m}$ above mean sea level [34]; around $16 \%$ of its total area 
is covered by a dense network of rivers and canals about $8000 \mathrm{~km}$ in length. In addition, the water levels in these widespread waterways are primarily affected by a combination of semi-diurnal tides, extreme monsoon rainfalls and storms across the city. Consequently, the low-lying terrain accompanying the open and unrestrained water systems in HCMC poses serious threats of flooding vulnerability to the city, especially in the context of climate change [35].

\subsection{Data Preparation}

The historical daily precipitation data during the period of 1980-2017 provided by the Hydro-Meteorological Data Center of Vietnam were collected at 11 meteorological stations in HCMC and adjacent regions, as shown in Figure 1.

In this study, the basic quality controls and homogeneity assessment were applied to both the observed and projected datasets in order to secure the completeness, reliability, and consistency of the data before computing selected extreme precipitation indices and performing trend analysis. To assess the quality and homogeneity of meteorological data, as well as to compute the climatic extreme indices, the RClimdex statistical toolkit and RHtests toolkit [36] are used. The RClimadex and RHtests are the libraries for computing 27 core extreme climate indices [21] and testing the data homogenization. These toolkits are accepted and recommended by the World Meteorology Organization [37].

\section{Methodology}

\subsection{Extreme Precipitation Indices}

To assess the spatial and temporal variability of trends in extreme rainfall events across $\mathrm{HCMC}$, the well-known extreme precipitation indices suggested by the Expert Team on Climate Change Detection and Indices (ETCCDI) were used in this study. Since the HCMC is located in tropical climate region, a set of 8 appropriate extreme precipitation indices (Rx1day, Rx5day, CDD, CWD, R20mm, R25mm, R95p, and SDII), as shown in Table 1, is chosen in order to evaluate the elemental characteristics of extreme precipitation events, such as intensity, duration, and frequency. Particularly, R20 $\mathrm{mm}$ and R25mm indicate the frequency of extreme rainfall; CDD and CWD describe the duration of extreme rainfall; RX1day, RX5day, R95p, and SDII present the intensity of extreme rainfall. These extreme indices were selected based on the previous studies [38].

Table 1. List of precipitation extreme indices used in this study.

\begin{tabular}{|c|c|c|c|c|}
\hline Types & Indices & Name & Definitions & Unit \\
\hline \multirow{4}{*}{ Intensity indices } & RX1day & Max 1-day precipitation amount & Monthly maximum 1-day precipitation & $\mathrm{mm}$ \\
\hline & RX5day & Max 5-day precipitation amount & Monthly maximum 5-day precipitation & $\mathrm{mm}$ \\
\hline & R95p & Very wet days & $\begin{array}{l}\text { Annual total precipitation when } \\
\text { precipitation }>95 \text { th percentile }\end{array}$ & $\mathrm{mm}$ \\
\hline & SDII & Simple daily intensity index & $\begin{array}{l}\text { Annual total precipitation divided by the } \\
\text { number of wet days }\end{array}$ & $\mathrm{mm} /$ day \\
\hline \multirow{2}{*}{ Frequency indices } & $\mathrm{R} 20 \mathrm{~mm}$ & $\begin{array}{l}\text { Number of heavy precipitation } \\
\text { days }\end{array}$ & $\begin{array}{l}\text { Annual count of days when precipitation } \\
\qquad>20 \mathrm{~mm}\end{array}$ & days \\
\hline & $\mathrm{R} 25 \mathrm{~mm}$ & $\begin{array}{l}\text { Number of very heavy } \\
\text { precipitation days }\end{array}$ & $\begin{array}{l}\text { Annual count of days when precipitation } \\
\qquad>25 \mathrm{~mm}\end{array}$ & days \\
\hline \multirow{2}{*}{ Duration indices } & CDD & Consecutive dry days & $\begin{array}{l}\text { Maximum number of consecutive days } \\
\text { with precipitation }<1 \mathrm{~mm}\end{array}$ & days \\
\hline & CWD & Consecutive wet days & $\begin{array}{l}\text { Maximum number of consecutive days } \\
\text { with precipitation }>1 \mathrm{~mm}\end{array}$ & days \\
\hline
\end{tabular}


These selected indices were computed by RClimdex tool for each station of the 11 weather stations in HCMC based on the corresponding datasets of historical observation and the future projections. Thereby, the trend analysis approach was used to provide valuable information about the spatial and temporal change of trends in extreme precipitation events due to the impact of climate change in the study region.

\subsection{Trend Analysis}

\subsubsection{Mann-Kendall Test}

For analyzing the underlying tendency in climate and hydrological data series, the Mann-Kendall (M-K) nonparametric test [39,40] and Sen's estimator [41] are highly recommended by the World Meteorological Organization (WMO) and widely applied in most studies on the trend analysis of hydro-meteorological data [32,42]. Additionally, the nonparametric M-K test was selected for the present study instead of parametric tests, because this method is suitable for the hydro-meteorological data with a non-normal distribution, and it has low sensitivity to abrupt breaks due to the inhomogeneity of data [42]. The M-K hypothesis test is based on the assumptions that the data need to be independent and identically distributed, i.e., there is no serial autocorrelation remains in the datasets [43]. The statistic parameter (Z-score) computed from the M-K test was used to detect the movement of trends (increasing or decreasing tendency); the corresponding $p$-value indicates the level of statistical significance, whereas Sen's slope was calculated to represent the magnitude of trends.

Prior to applying the M-K test and Sen's estimator, the study datasets were examined for the existence of serial autocorrelation to reduce the adverse impact on the detection of deterministic trends. In this study, the trend-free pre-whitening approach (TF-PW) was conducted in order to remove the serial autocorrelation effects; the detailed definition and procedure of this method can be found in [44,45].

\subsubsection{Trend Strength and Stability}

An advantage of using the M-K test for trend analysis is the test results being rarely affected by outliers; it is not restricted to a specific sample distribution. However, the determined sign and magnitude of a trend are strongly depended on a selected time period, i.e., the trend's test results will be changed as the time span of the dataset is varied. Hence, it is challenging to evaluate the tendency of a time series due to the instability of the test results [31,32]. Therefore, the traditional M-K test should be modified for assessing a long-term persistence of the statistical significance and stability of the trend. The choice of studying trends in 25-year moving periods was intended as a cross-validation technique for time series data. The rainfall data of a station were recognized to have a predominantly upward (or downward) trend if the number of 25-year moving time series with significantly upward (or downward) trends was higher than the number of significantly downward (or upward) trends. In this study, the M-K test and Sen's estimator were sequentially applied at each station for each interval of 25-year moving time series of extreme precipitation indices within the historical (1980-2017), the baseline (1980-2009), near future (2021-2050) and intermediate future (2051-2080) periods. In detail, there are 14 series of 25-year intervals regarding the historical observed data from the period of (1980-2004) to (1993-2017), 6 series of 25-year intervals regarding simulated baseline data from the period of (1980-2004) to (1985-2009), and 12 series of 25-year intervals regarding simulated future data from the period of (2021-2045) to (2026-2050) and from the period of (2051-2075) to (2056-2080), respectively.

The statistical significance of a trend was classified by the $p$-value, which is computed by the M-K test following statistical classification as a strongly significant trend if $p<0.1$, a weakly significant trend if $0.1 \leq p \leq 0.2$, and an insignificant trend if $p>0.2$ [32]. In addition, a particular trend, e.g., significant increasing/decreasing or insignificant trend, with the greatest number of 25-year moving periods, was recognized as the dominant trend at a specific station for spatial analysis. Thereby, the stability (S) of a significant 
increasing/decreasing trend in each extreme precipitation indices at a station was expressed as the percentage of the 25-year moving time series, in which their trends were significantly increasing/decreasing during a particular period. The determined stability of trends was categorized as an unstable trend if $0 \% \leq \mathrm{S} \leq 15 \%$; a poor trend if $15 \% \leq \mathrm{S} \leq 25 \%$; a stable trend if $25 \% \leq \mathrm{S} \leq 50 \%$; strongly stable if $50 \% \leq \mathrm{S} \leq 75 \%$; very strongly stable if $S \geq 75 \%$. In this study, the arithmetic average of the slope values, which were computed by Sen's estimator for each interval of 25-year moving periods, was taken to express an average magnitude of a trend in each extreme precipitation indices at each station during the particular periods. The detailed description of this approach could be found in [31,32].

\subsection{LARS-WG Downscaling Tool}

There are various statistical downscaling techniques, such as the Statistics Downscaling Model (SDSM), Automated Statistical Downscaling (ASD), delta change methods, etc.; among them, LARS-WG developed by Semenov and Stratonovitch [46] was selected for this study because it can provide a better performance on reproducing monthly meteorological variables than other statistical downscaling techniques [47]. Basically, LARS-WG uses observed meteorological data (daily rainfall, temperature) from a specified site to estimate a set of parameters for fitting probability distributions, which is then used to generate synthetic weather time series of a tributary length by randomly selecting values from appropriate distributions [48]. Based on the coordinates of the meteorological station, the LARS-WG tool automatically determines the match between the station and GCM grid cell to generate a site-specific scenario of climate change using the GCM outputs, even though the size of the GCM grid cells is larger than that of the study area. To produce the climate change scenarios, the distribution parameters for a specific site were perturbed with the monthly delta factors of each future period derived from the GCM output. The delta factors are estimated as relative changes in precipitation. The LARS-WG has been widely applied as a downscaling tool to generate future climate data from general circulation models (GCMs) for climate change assessments in numerous studies, and it has confirmed a good efficiency in simulating the extreme precipitation [49-51]. More discussion on the applications of the LARS-WG tool for climatic extreme event analysis could be found in various studies, such as $[46,52,53]$.

By using the historical observed rainfall data, LARS-WG was sequentially applied to estimate a set of parameters for the semi-empirical probability distributions of precipitation data at each station in the study area. These probability distributions were used for fitting the sequences of wet and dry days and precipitation amount. Thereby, the site-calibrated parameters were used to simulate daily precipitation at each rain gauge for the baseline period. To evaluate the performance of LARS-WG in simulating the rainfall, statistical analysis of observed and simulated rainfall data was conducted. In order to generate the future climate scenarios, LARS-WG modifies the historical rainfall data by adding monthly change factors (the ratio of rainfall in the future and baseline periods) [52].

In this study, five GCMs from the Coupled Model Intercomparison Project Phase 5 (CMIP5) multi-model ensemble, which were incorporated in LARS-WG, were used to generate the climate change scenario for the study area. The RCP8.5 scenario was chosen for the present study, as it corresponds to the worst-case climate change scenario caused by the highest greenhouse emission and radiative forcing level $\left(8.5 \mathrm{Wm}^{-2}\right)$ in 2100 . Since the purpose of this study is mainly focused on the analysis of extreme events, the RCP8.5 was considered as a plausible selection [54]. The list of five GCMs used in this study is presented in Table 2 . The downscaled daily precipitation data from GCM outputs under RCP8.5 scenario was generated by LARS-WG for the near (2021-2050) and intermediate (2051-2080) future periods of the 21st century at each station of 11 meteorological stations in HCMC. 
Table 2. The descriptions of the general circulation models (GCMs) from Coupled Model Intercomparison Project 5 (CMIP5) used in the study.

\begin{tabular}{cccc}
\hline GCMs & Research Center & Country & Resolution \\
\hline EC-EARTH & EC-Earth consortium & Europe & $1.125^{\circ} \times 1.125^{\circ}$ \\
\hline HadGEM2-ES & UK Meteorological Office & $\mathrm{UK}^{\circ}$ & $1.25^{\circ} \times 1.88^{\circ}$ \\
\hline GFDL-ESM2M & Geophysical Fluid Dynamics Laboratory (NOAA GFDL) & USA & $2.5^{\circ} \times 2.0^{\circ}$ \\
\hline MIROC5 & $\begin{array}{r}\text { The University of Tokyo, National Institute for } \\
\text { Environmental Studies, Japan Agency for Marine-Earth } \\
\text { Science and Technology }\end{array}$ & Japan & $1.39^{\circ} \times 1.41^{\circ}$ \\
\hline MPI-ESM-MR & Max Planck Institute for Meteorology & Germany & $1.85^{\circ} \times 1.88^{\circ}$ \\
\hline
\end{tabular}

\subsection{Model Evaluation Metrics}

In this study, the performance of LARS-WG was evaluated according to the relative bias (RB), the mean differences (MDs), and Willmott Score (WS) [55] between the observation-based and simulation-based series of corresponding extreme precipitation indices. The mathematical formulas of those evaluation metrics are as follows:

$$
\begin{gathered}
R B=\frac{\sum_{n=1}^{N}\left(\operatorname{Mod}_{n}-O b s_{n}\right)}{\sum_{n=1}^{N}\left|O b s_{n}\right|} \\
M D=\frac{1}{N} \sum_{n=1}^{N}\left(\operatorname{Mod}_{n}-O b s_{n}\right) \\
W S=1-\frac{\frac{1}{N} \sum_{n=1}^{N}\left(\operatorname{Mod}_{n}-O b s_{n}\right)^{2}}{\frac{1}{N} \sum_{n=1}^{N}\left(\left|\operatorname{Mod}_{n}-\overline{O b s}\right|+\left|O b s_{n}-\overline{O b s}\right|\right)^{2}}
\end{gathered}
$$

where $\mathrm{Mod}_{n}$ and $\mathrm{Obs}_{n}$ are the values of the $n^{\text {th }}$ simulation-based and observation-based extreme precipitation indices in a sample of size $N$, respectively.

The mean difference (MD) is used for a direct comparison between the observed and generated extreme indices, while the two-sample Student's t-test is applied for testing the statistical significance of those differences at the $95 \%$ confidence level. The relative bias (RB) is used to measure the relative differences between the observed and generated extreme indices, as well as to determine the overestimated or underestimated property of the simulation. According to the study of Moriasi et al. [56], the values of RB $\leq \pm 25 \%$ indicate an acceptable performance of the model and the MD values of 0 indicate a perfect performance of the model. The Willmott score (WS) or the Index of Agreement, whose value varies between 0 and 1 , is used as a standardized measurement of the degree of model prediction error [57]. Particularly, the levels of model performance are classified in a poor level if $0 \leq \mathrm{WS}<0.3$, a good level if $0.3 \leq \mathrm{WS}<0.8$, and an excellent level if $0.8 \leq \mathrm{WS} \leq 1.0$.

\subsection{Spatial Interpolation}

The maps of extreme rainfall indices were built using interpolated techniques of inverse distance weighting (IDW). This method had the assumption that the interpolated points are the most influenced by the nearest points and the least influenced by the farthest points. The IDW method was chosen for the present study, because it is widely applied to spatial interpolation of rainfall data [58]; particularly it is applied to HCMC, whose topography is mostly plain, and the orographic effect is negligible. 


\section{Results and Discussion}

\subsection{Model Validation}

In this section, the ability of the LARS-WG tool for reproducing extreme precipitation indices was evaluated at each station for the baseline period of 1980-2009. Generally, the results indicated the ability of the LARS-WG tool for reproducing the extreme indices as its Willmott scores belonged to the good performance level (WS $>0.3$ ) in most regions as shown in Figure 3; the results of the $t$-test indicated that only few stations in the study area (less than $36 \%$ of stations) obtained statistically significant differences between the observation and simulation values, as shown in Table 3. Particularly, regarding the indices CDD and CWD, the results of the Willmott scores indicated good agreement between the simulation and observation as the WS values exceeded 0.3 for the entire region (ranged from 0.31 to 0.57 ), whereas the index CWD shows the worst performance among other indices as only good WS values (ranged 0.33 to 0.62 ) obtained at 6 out of 11 stations in the research area. Furthermore, the relative bias indicated the underestimation of the index CDD for most regions, especially in the central parts, whereas the overestimation of the index CWD was observed in the same regions. Concerning the indices, RX1day and RX5day, the high WS values (ranged from 0.33 to 0.67 ) and small negative biases were apparent at most parts in the southern and central regions, whereas the lower WS values (ranged from 0.17 to 0.28 ), as well as large positive biases, occurred in small parts of the northern regions. About the indices, R20mm, R25mm, R95p, and SDII, the simulation generally showed good performance as the WS values exceeded 0.3 for most regions (ranged from 0.31 to 0.64 ), except in some parts in the central region the WS values were observed slightly weaker scores (ranged from 0.14 to 0.28). Additionally, Figure 3 and Table 3 show that the high values of WS are not always related to the lesser difference between simulation-based and observation-based extreme indices (low values of RB and $\mathrm{MD})$ as shown in Equations (1)-(3).

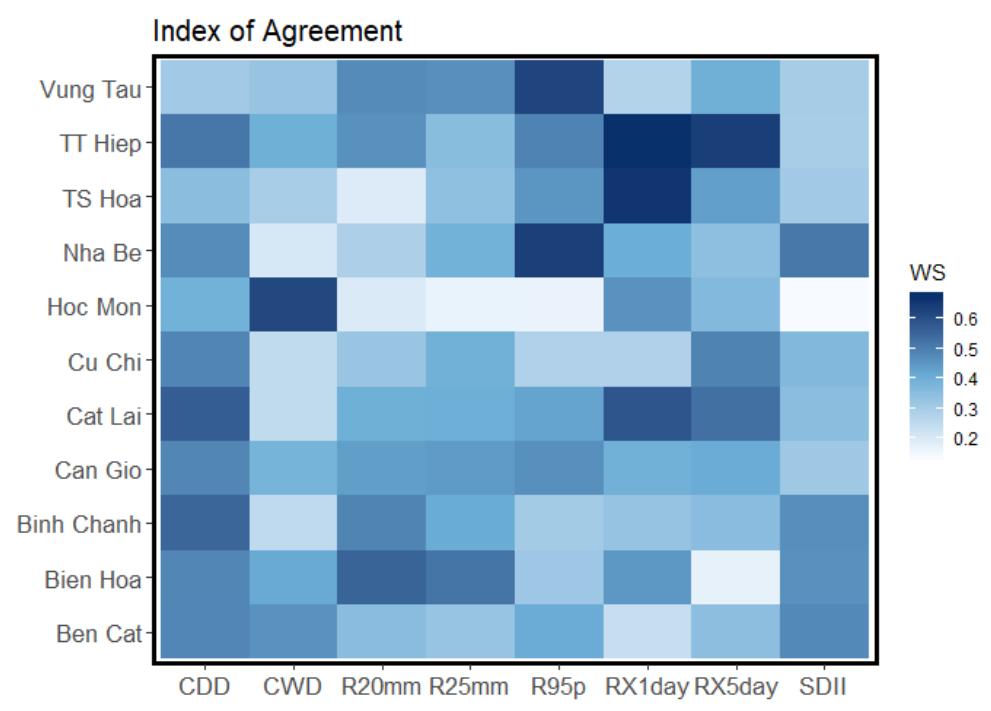

Figure 3. Heatmap of the Willmott scores between observed and simulated extreme indices at each station for the baseline period (1980-2009). 


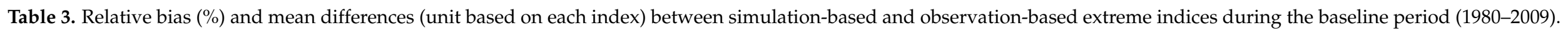

\begin{tabular}{|c|c|c|c|c|c|c|c|c|c|c|c|c|c|c|c|c|}
\hline \multirow{2}{*}{$\begin{array}{c}\text { Station } \\
\text { Paras }\end{array}$} & \multicolumn{2}{|c|}{ CDD } & \multicolumn{2}{|c|}{ CWD } & \multicolumn{2}{|c|}{$\mathrm{R} 20 \mathrm{~mm}$} & \multicolumn{2}{|c|}{$\mathrm{R} 25 \mathrm{~mm}$} & \multicolumn{2}{|c|}{ R95p } & \multicolumn{2}{|c|}{ RX1day } & \multicolumn{2}{|c|}{ RX5day } & \multicolumn{2}{|c|}{ SDII } \\
\hline & RB & MD & RB & MD & RB & MD & RB & MD & RB & MD & RB & MD & RB & MD & RB & MD \\
\hline Ben Cat & 6.8 & 6.0 & -20.4 & $-2.1 *$ & -7.5 & -2.3 & -6.3 & -1.4 & -11 & 1.4 & 3.6 & 3.1 & -0.1 & -0.2 & -0.5 & -0.1 \\
\hline Bien Hoa & -32.2 & $-33.2 *$ & 65.5 & $3.7^{*}$ & 16.3 & $3.9 *$ & 9.9 & 1.9 & 25.7 & 101.6 * & 6.2 & 6.1 & 7.3 & 11.6 & -15 & -2.8 * \\
\hline Binh Chanh & -7.9 & -6.9 & 5 & 0.4 & 9.5 & 2.3 & 16.5 & $3.0 *$ & -7.3 & -27.9 & 16.9 & 15.0 & 7.4 & 11.3 & 8.8 & $1.2 *$ \\
\hline Can Gio & 1.8 & 2.1 & -8.2 & -0.8 & -52.7 & $-11.7 *$ & -35.2 & $-3.8 *$ & -38 & -16.6 & 20.3 & 13.0 & -17.5 & $-23.6 *$ & -35 & $-6.0 *$ \\
\hline Cat Lai & -16.7 & -15.8 & 2.4 & 0.2 & -43.2 & $-23.7 *$ & -49 & $-22.5 *$ & -27 & -98.2 & 1.4 & 1.7 & -18.4 & $-44.0 *$ & -37 & $-11.9 *$ \\
\hline $\mathrm{Cu}$ Chi & -19.3 & $-18.5 *$ & 0.4 & 0.0 & -1.4 & -0.4 & -1.4 & -0.3 & 7.9 & 44.4 & 25.9 & $22.0 *$ & 0.9 & 1.5 & -4.2 & -0.7 \\
\hline Hoc Mon & 1.5 & 1.4 & 6.5 & 0.5 & 3.7 & 0.8 & 8.4 & 1.4 & -3.2 & -0.5 & -1.7 & -1.6 & -4.5 & -6.9 & 1.6 & 0.2 \\
\hline Nha Be & -13.7 & -12.1 & 12.1 & 1.0 & 3.2 & 0.9 & -0.4 & -0.1 & -8.9 & -14.1 & -5.9 & -5.8 & -5.1 & -8.6 & 3.3 & 0.5 \\
\hline TS Hoa & -20.5 & -15.9 & 15.8 & $1.6^{*}$ & -4 & -1.3 & -3.1 & -0.8 & 5.6 & 24.4 & -0.2 & -0.3 & -7.4 & -13.4 & -1.8 & -0.3 \\
\hline TT Hiep & -11.2 & -11.2 & -11.6 & -1.0 & -0.6 & -0.2 & -4.5 & -0.9 & -14 & -48.6 & -5.5 & -5.3 & -10.1 & -17.4 & 0.1 & 0.0 \\
\hline Vung Tau & -24.5 & $-27.6^{*}$ & -15.2 & -1.5 & 5.4 & 1.3 & 7.1 & 1.3 & 8.5 & 31.6 & 10.2 & 11.3 & 9.5 & 16.7 & 4.7 & 0.7 \\
\hline
\end{tabular}

* Statistically significant difference at the $95 \%$ confidence level. 
In addition, Figure 6(6.1-6.8) show the spatial distribution of the observation (Figure 6(6.1a-6.8a)) and simulation (Figure 6(6.1b-6.8b)) extreme precipitation indices during the baseline period (1980-2009), and relative differences between the simulation and observation (Figure 6(6.1c-6.8c)). In general, the spatial distribution of the differences between simulation and observation under those indices had similar trends-here, large negative biases were apparent in small parts of the central and southern regions, while positive biases mainly occurred in other regions. General speaking, the results show that the output from the LARS-WG tool is acceptable for simulating the spatial pattern of the extreme indices.

\subsection{The Historical Observation of the Extreme Precipitation Indices}

In this section, the mean annual values of each extreme indices and the corresponding averaged slope of temporal trends during the historical period (1980-2017) at each station in the study area were listed in Table 4. Generally, most extreme indices exhibited downward trends at most stations of the study area during this period, which accounted for approximately $56.8 \%$ of the total number of the trends. However, only about one-third proportion (approximately 33\%) of all trends were statistically significant; in which the significant downward and upward trends accounted for $19.3 \%$ and $13.6 \%$ proportion, respectively.

About the spatial distribution patterns, a majority of the significant trends frequently occurred in the northern (Cu Chi Dist.) and southern (Can Gio Dist.) parts of the study area, whereas most of the central regions demonstrated insignificant trends (Table 4).

\subsection{Projected Future Extreme Precipitation Indices}

In this study, the future extreme precipitation indices were calculated from the statistically downscaled outputs of five GCMs (EC-EARTH, HadGEM2-ES, GFDL-ESM2M, MIROC5, and MPI-ESM-MR) as mentioned in Section 3.3 above. The daily rainfall at each station in the study area was generated for the future period of 2021-2080 under the RCP8.5 emission scenario. The temporal variation of each spatially averaged extreme index for the entire study area during the future period was illustrated in Figure 4. According to the results, while two duration-based indices, CDD and CWD, show a high degree of agreement among the five GCMs, the other extreme precipitation indices are generally projected with high uncertainty levels, especially in the intermediate future period (20512080). Particularly, three GCMs such as MIROC5, MPI-ESM-MR, and EC-Earth projected higher values of extreme indices than two other GCMs, HadGEM2-ES and GFDL-ESM2M.

However, the multi-model ensemble mean generally presents the obviously increasing trends in value at the majority of extreme precipitation indices during both future periods lasting from 2021 to 2080 for the entire study area.

\subsection{Climate Change Impact on the Precipitation Extremes by the Averaged Multi-Model Ensemble}

\subsubsection{Variability in Inter-Annual Changes}

To produce more reliable results from simulation of extreme precipitation indices for assessing the impact of climate change, a multi-model ensemble (MME) at each station is prepared by taking the arithmetic mean of the extreme indices computed from the output from the five different GCMs mentioned in the previous section. 


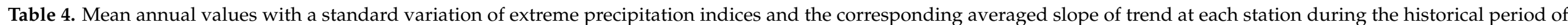
1980-2017 in Ho Chi Minh City (HCMC).

\begin{tabular}{|c|c|c|c|c|c|c|c|c|c|}
\hline Indices & Stats & CDD & CWD & $\mathrm{R} 20 \mathrm{~mm}$ & $\mathrm{R} 25 \mathrm{~mm}$ & R95p & RX1day & RX5day & SDII \\
\hline \multirow{2}{*}{ Unit } & Mean \pm SD & days & days & days & days & $\mathrm{mm}$ & $\mathrm{mm}$ & $\mathrm{mm}$ & $\mathrm{mm} /$ day \\
\hline & Avg. Trend & days/year & days/year & days/year & days/year & $\mathrm{mm} /$ year & $\mathrm{mm} /$ year & $\mathrm{mm} /$ year & $\mathrm{mm} /$ day/year \\
\hline \multicolumn{10}{|c|}{ North Region } \\
\hline \multirow{2}{*}{$\mathrm{Cu}$ Chi } & Mean \pm SD & $97.1 \pm 37.8$ & $8.4 \pm 3.6$ & $28.4 \pm 6$ & $22.1 \pm 5.1$ & $343.9 \pm 192$ & $86.7 \pm 27.6$ & $161.7 \pm 34.9$ & $16.9 \pm 3.1$ \\
\hline & Avg. Trend & -0.44 & -0.11 & $-0.24 *$ & $-0.18 *$ & $-12.63 *$ & 0.37 & $-1.78 *$ & $-0.09 *$ \\
\hline Hoc Mon & Mean \pm SD & $86.5 \pm 43.6$ & $7.9 \pm 3.5$ & $23.6 \pm 8.8$ & $17.2 \pm 7.3$ & $327.6 \pm 211.5$ & $90.1 \pm 25.9$ & $153.4 \pm 42.7$ & $15 \pm 4$ \\
\hline \multicolumn{10}{|c|}{ Central Region } \\
\hline \multirow{2}{*}{ Binh Chanh } & Mean \pm SD & $82 \pm 41.6$ & $8.9 \pm 2.7$ & $24.8 \pm 6.5$ & $17.9 \pm 5.9$ & $370.9 \pm 226.8$ & $88 \pm 33.5$ & $155 \pm 39.8$ & $13.7 \pm 2.1$ \\
\hline & Avg. Trend & -1.28 & 0.01 & 0.2 & $0.22 *$ & 3.05 & -0.35 & 0.63 & 0.01 \\
\hline \multirow{2}{*}{ Cat Lai } & Mean \pm SD & $89.8 \pm 38.6$ & $6.8 \pm 3.6$ & $53.5 \pm 14.5$ & $44.2 \pm 13.1$ & $405.7 \pm 322.5$ & $114.2 \pm 32.2$ & $232 \pm 67.4$ & $31.3 \pm 5.2$ \\
\hline & Avg. Trend & -0.63 & $-0.11 *$ & -0.21 & -0.4 & $-14.91 *$ & -0.56 & -2.83 & $-0.37 *$ \\
\hline Nha Be & Mean \pm SD & $84.1 \pm 41.7$ & $8.5 \pm 2.3$ & $28.2 \pm 7.2$ & $21.6 \pm 5.9$ & $411.1 \pm 251.6$ & $98.8 \pm 33.1$ & $172.1 \pm 41.1$ & $15.7 \pm 2.4$ \\
\hline \multirow{2}{*}{ Tan Son Hoa } & Mean \pm SD & $73.8 \pm 38$ & $10.2 \pm 2.5$ & $32.4 \pm 5.7$ & $25.1 \pm 4.6$ & $464.2 \pm 205.1$ & $104 \pm 28.4$ & $185.6 \pm 39.8$ & $15.5 \pm 1.7$ \\
\hline & Avg. Trend & -0.32 & -0.07 * & -0.05 & -0.02 & 3.87 & 0.39 & -0.44 & 0.01 \\
\hline \multicolumn{10}{|c|}{ South Region } \\
\hline \multirow{2}{*}{ TT Hiep } & Mean \pm SD & $93.1 \pm 45.1$ & $9.2 \pm 3.6$ & $26.2 \pm 5$ & $19.7 \pm 4.7$ & $364.8 \pm 160.4$ & $97.4 \pm 39.8$ & $168.8 \pm 48.4$ & $15.8 \pm 2.4$ \\
\hline & Avg. Trend & $-1.67^{*}$ & $0.13 *$ & -0.01 & -0.03 & 1.51 & -0.39 & -0.89 & $-0.15 *$ \\
\hline \multirow{2}{*}{ Can Gio } & Mean \pm SD & $120.3 \pm 32.9$ & $8.9 \pm 3.4$ & $22.3 \pm 8.2$ & $11.9 \pm 7.1$ & $288.7 \pm 255.7$ & $69.7 \pm 39$ & $138.5 \pm 34.3$ & $16.4 \pm 2.1$ \\
\hline & Avg. Trend & -0.08 & -0.03 & -0.04 & $0.4^{*}$ & $16.62 *$ & $2.01 *$ & $1.97 *$ & $-0.14 *$ \\
\hline
\end{tabular}


Table 4. Cont.

\begin{tabular}{|c|c|c|c|c|c|c|c|c|c|}
\hline Indices & Stats & CDD & CWD & $\mathrm{R} 20 \mathrm{~mm}$ & $\mathrm{R} 25 \mathrm{~mm}$ & R95p & RX1day & RX5day & SDII \\
\hline \multicolumn{10}{|c|}{ Neighborhood Region } \\
\hline Ben Cat & Mean \pm SD & $89.3 \pm 35.9$ & $10.1 \pm 3.3$ & $30.7 \pm 7.5$ & $22.1 \pm 6.4$ & $389.2 \pm 233.1$ & $90.4 \pm 33.5$ & $160.6 \pm 38.4$ & $15.8 \pm 2$ \\
\hline \multirow{2}{*}{ Bien Hoa } & Mean \pm SD & $95.2 \pm 42.2$ & $6.6 \pm 2.9$ & $25.6 \pm 8.5$ & $20.3 \pm 6.7$ & $331.2 \pm 189.5$ & $100.6 \pm 29.4$ & $162 \pm 50$ & $17.5 \pm 2.8$ \\
\hline & Avg. Trend & $-2.35 *$ & $0.22 *$ & $0.62 *$ & $0.45 *$ & $8.11 *$ & 0.55 & $2.68 *$ & $-0.11 *$ \\
\hline \multirow{2}{*}{ Vung Tau } & Mean \pm SD & $108.9 \pm 38.4$ & $9.7 \pm 3.4$ & $23.1 \pm 5.2$ & $17.5 \pm 4.2$ & $358.5 \pm 127.1$ & $110.1 \pm 44.1$ & $173.5 \pm 49.6$ & $15.1 \pm 2$ \\
\hline & Avg. Trend & -0.49 & 0.03 & $-0.29 *$ & $-0.19 *$ & -3.84 & -1.52 & -1.38 & $-0.11 *$ \\
\hline
\end{tabular}



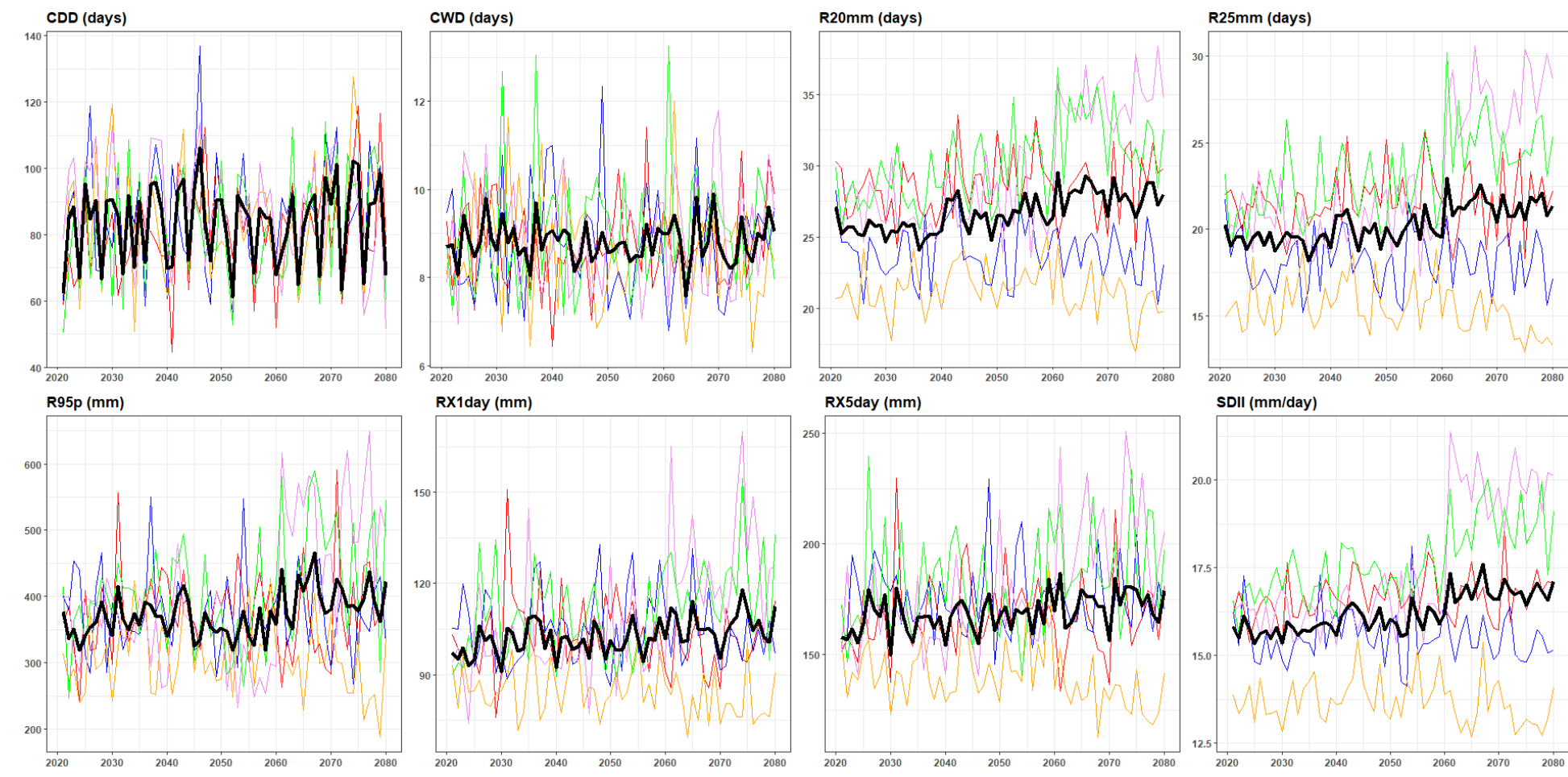

SDII (mm/day)

GCMs - EC-Earth - HadGEM2

\section{- MPI-ESM-MR}

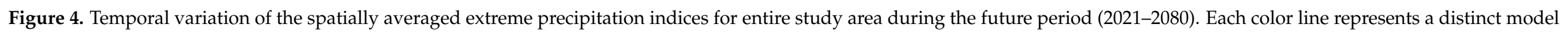
while the bold and black line indicates the multi-model ensemble mean. 
In the following section, the temporal variation of percentage changes in each extreme precipitation indices between the future (2021-2080) and baseline (1980-2009) periods over the entire study area is analyzed and discussed. The temporal variation of changes in spatially averaged MME extreme indices and its corresponding magnitude of linear trend in each future period were illustrated in Figure 4 and Table 5. As shown in Table 5, the decreasing trend is projected in most extreme precipitation indices during the near future period, while the opposite tendency mainly occurs during the intermediate future period. However, except for the index CDD, the temporal variation of relative changes in other extreme indices is expected to be increased during both near (2021-2050) and intermediate (2051-2080) future periods, in which only four extreme indices, R20mm, R25mm, RX5day, and SDII, show the statistically significant trends.

Table 5. Trend in relative change between future and baseline periods (unit: \% per decade).

\begin{tabular}{cccccccccc}
\hline Period & CDD & CWD & R20mm & R25mm & R95p & RX1day & RX5day & SDII \\
\hline $2021-2050$ & 2.02 & -0.25 & -0.77 & -0.34 & -5.54 & -0.69 & 2.21 & -0.55 \\
\hline $2051-2080$ & 0.83 & 1.04 & -0.26 & 1.82 & 0.28 & 0.79 & 2.69 & 0.65 \\
\hline
\end{tabular}

Figure 5 illustrates the temporal variation of the relative changes in the spatially averaged extreme indices between the future and baseline periods over the entire study area. Figure 5 shows the multi-model ensemble mean with 5-95\% interquartile range of five different GCMs under RCP8.5 scenario. Considering the duration extreme indices, the tendency of the index CDD presents an obviously increasing trend in both future periods; while CWD gradually tends to decrease in the near future period, then slightly increase in the intermediate future period. Particularly, the annual mean value of the percentage changes in CDD indicates an increase by $0.15 \%$ (from $-16.05 \%$ to $16.80 \%$ ) in the near future period (2021-2050), and by $0.7 \%$ (from $-12.46 \%$ to $14.73 \%$ ) in the intermediate future period (2051-2080). In contrast, the future index CWD is expected to increase by $4.07 \%$ (from $-10.21 \%$ to $20.52 \%$ ) and by $3.76 \%$ (from $-8.63 \%$ to $17.34 \%$ ) at the end of the near and intermediate future periods with respect to those of the reference period.

In regard to the indices of heavy and extreme heavy precipitation days, $\mathrm{R} 20 \mathrm{~mm}$ and $\mathrm{R} 25 \mathrm{~mm}$, the annual changes in the future are comparatively similar with respect to the baseline period. The length of heavy and extremely heavy rainfall days is expected to be shortened during the near future period (2021-2050) with the projected decrease in $\mathrm{R} 20 \mathrm{~mm}$ and $\mathrm{R} 25 \mathrm{~mm}$ by $-2.67 \%$ (from $-18.46 \%$ to $10.52 \%$ ) and $-1.08 \%$ (from $-18.79 \%$ to $13.66 \%$ ), respectively. However, the MME predicts the indices R20mm and R25mm to be increased by $3.75 \%$ (from $-18.74 \%$ to $25.59 \%$ ) and $5.65 \%$ (from $-21.29 \%$ to $31.26 \%$ ) by 2080, respectively.

Concerning the indices RX1day and RX5day, it shows that the annual percentages of change in the near future period are slightly lower than those in the intermediate future period. Moreover, the index RX5day clearly shows the strongest increasing trend among other indices during both future periods with the mean value of percentage increase by $5.11 \%$ (from $-8.85 \%$ to $20.78 \%$ ) and $9.44 \%$ (from $-10.33 \%$ to $28.37 \%$ ) at the end of two future periods (in 2050 and 2080), respectively. Although the RX1day exhibits a downward trend during the early future period, an increase of $5.56 \%$ (from $-9.67 \%$ to $21.84 \%$ ) and $10.5 \%$ (from $-10.04 \%$ to $10.50 \%$ ) is predicted by the mean models at the end of the 2050 and 2080 periods, respectively. 

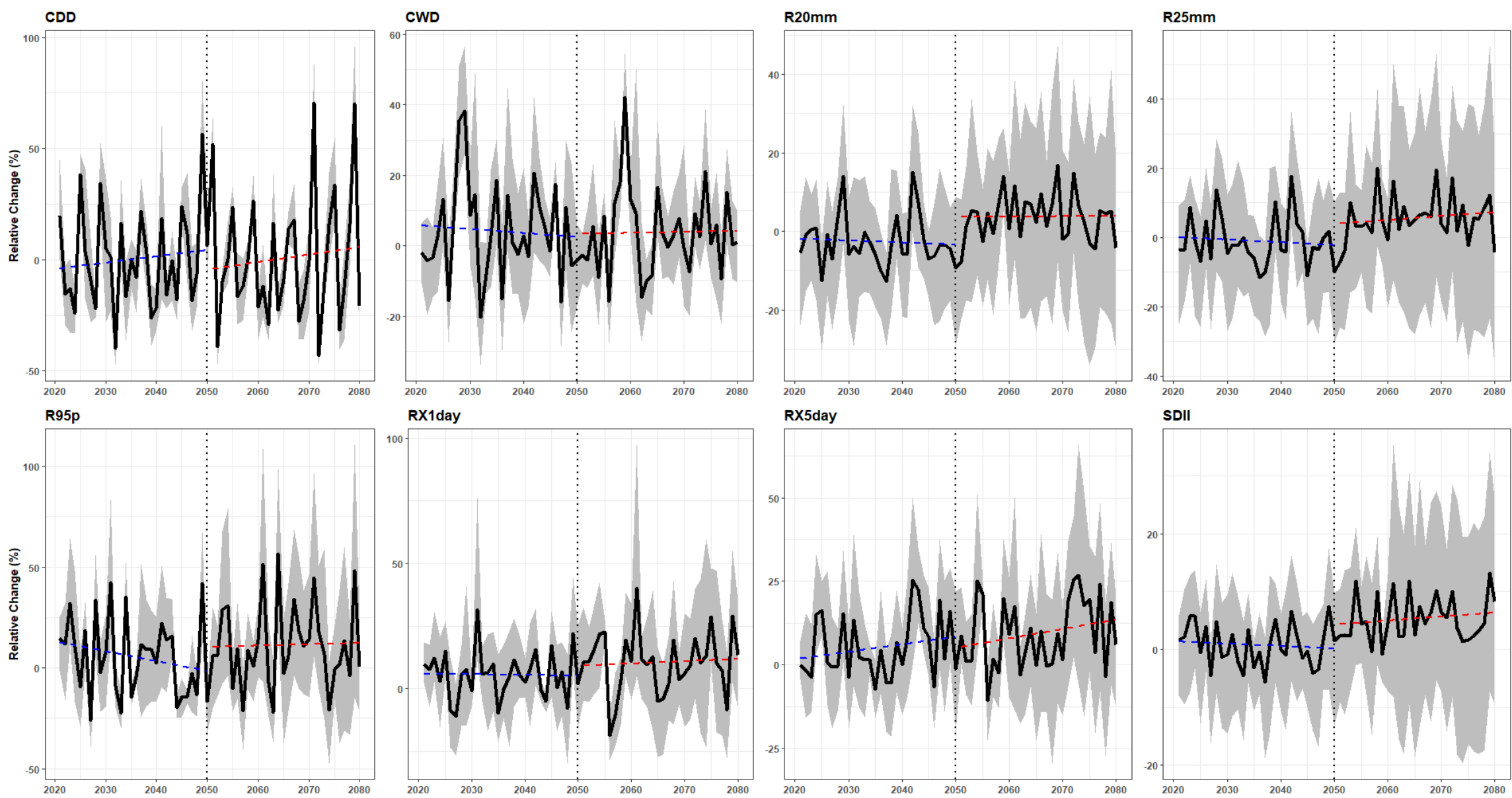

soll

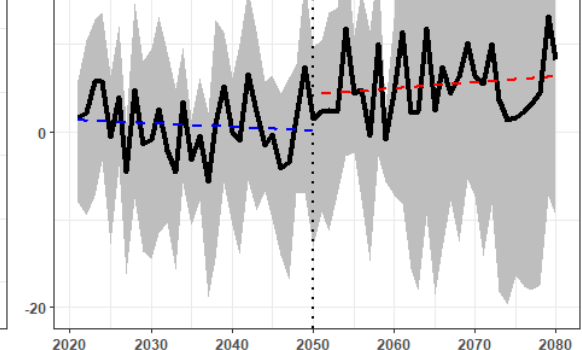

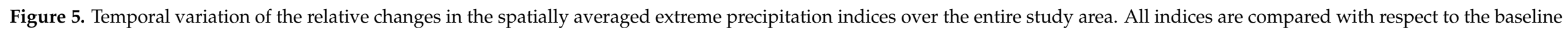

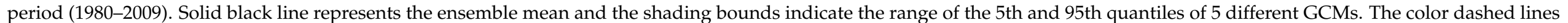
show the Mann-Kendall trends in each future period. 
About the extreme intensity indices, the predicted percentage of changes in the indices R95p and SDII approximately tend to be comparable behavior in the future, with a decreasing trend in the near future period, and an increasing tendency in the later future period. Both indices are projected to be increased in the future periods; however, the increasing percentage of the index R95p is much larger than the increasing percentage of the index SDII. Meanwhile, the multi-model ensemble predicts an increase of 5.5\% (from $-13.23 \%$ to $23.72 \%$ ) and $11.35 \%$ (from $-17.94 \%$ to $43.67 \%$ ) for the index R95p by 2050 and 2080, respectively. The percentage of change in SDII is projected to be $0.77 \%$ (from $-10.34 \%$ to $8.94 \%$ ) and $5.37 \%$ (from $-11.10 \%$ to $20.78 \%$ ) at the end of two future periods, respectively. Generally, the projected percentage changes, as well as the increasing rates in intensity and frequency indices for future extreme rainfall, are predicted to be larger than those in the duration indices, especially in the intermediate future period (2051-2080). In addition, the extreme precipitation indices show larger variation in the intermediate future period (2051-2080) in comparison to those in the near future period (2021-2050).

\subsubsection{Distribution of Spatial Changes}

In this section, the spatial distribution of the MME-projected mean relative changes in extreme precipitation indices between the near (2021-2050) and intermediate (2051-2080) future periods and the baseline period (1980-2009) over the study area is shown in Figure 6 including Figure 6(6.1-6.8). Furthermore, the statistical significance, stability, and magnitude of the trend in the distribution of spatial changes were determined and computed using the M-K statistical test and the Sen's estimator for particular 25-year moving time spans within the future periods. Afterwards, the dominated trend during these future periods at each station is also illustrated in these figures.

Generally, in comparison with the baseline period, the absolute changes of extreme indices in the intermediate future period (2051-2080) show notably higher than those in the near future period (2021-2050). In which, the largest absolute changes mainly occur in the southern regions, while some parts of the northern and central areas often exhibit little changes (i.e., lowest absolute changes). In terms of relative changes in extreme rainfall indices in the same projection period, the multi-model ensemble predicts an increase in most indicators in the south and the central regions, and a decline of those indices in the north of the study area.

Particularly, regarding the index CDD, the relative changes between the future and historical periods, along with the statistical significance, stability, and magnitude of trends, are shown in Figure 6(6.1). During the near future period (2021-2050), the averaged multimodel ensemble predicts an increase in the index CDD for most regions in the central and southern parts of the study area, whereby a variation of percentage changes in indices is from 0.4 to $20.6 \%$; the averaged growth rate is from 0.4 to 13.1 [days.decade $^{-1}$ ]. However, only three stations located in the southern region present significant increasing trends during the near future period, in which the strongest and most stable upward trend in CDD is predicted to occur at the Tam Thon Hiep Station. In contrast, a decrease ranging from -20.1 to $-8.7 \%$ is predicted in the northern regions, while $\mathrm{Cu}$ Chi Station shows a slight increase by 3.7\%; even though none of the downward trends is statistically significant. In the intermediate future period (2051-2080), the spatial distribution of the CDD is similar with that of the near future period in the study area, in which the positive percentage changes concentrate in the central and southern parts, while negative values are distributed mostly in the northern regions of the city. During this intermediate future period, the mean percentage of changes in CDD is predicted to decrease from -20.1 to $-1.7 \%$ at $\mathrm{Cu} C$ hi, Hoc Mon, Can Gio, Bien Hoa, and Ben Cat, and to increase from 1.82 to $21.8 \%$ at the other stations, whereby the averaged magnitude of increasing trend is ranging between 0.1 and 10.4 [days.decade ${ }^{-1}$ ] while the decreasing rate is from -2.9 to -0.8 [days.decade ${ }^{-1}$ ]. 


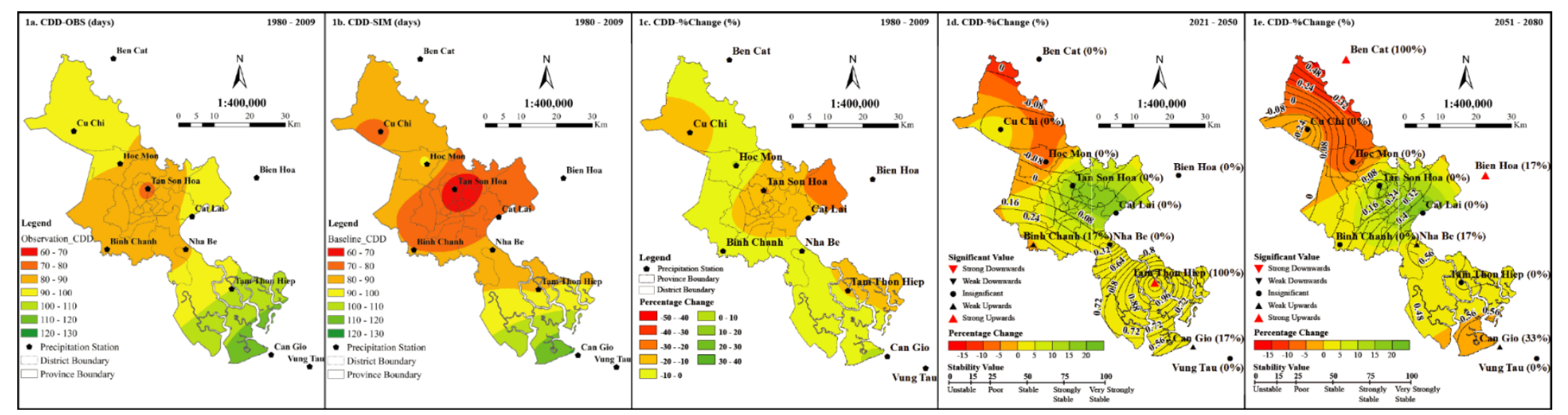

6.1 Spatial distribution of the observation (1a) and simulation (1b) extreme precipitation index (CDD) during the baseline period (1980-2009); relative differences between the simulation and observation (1c); relative changes between the near (2021-2050) and intermediate (2051-2080) future periods (1d,1e) with respect to the baseline period.

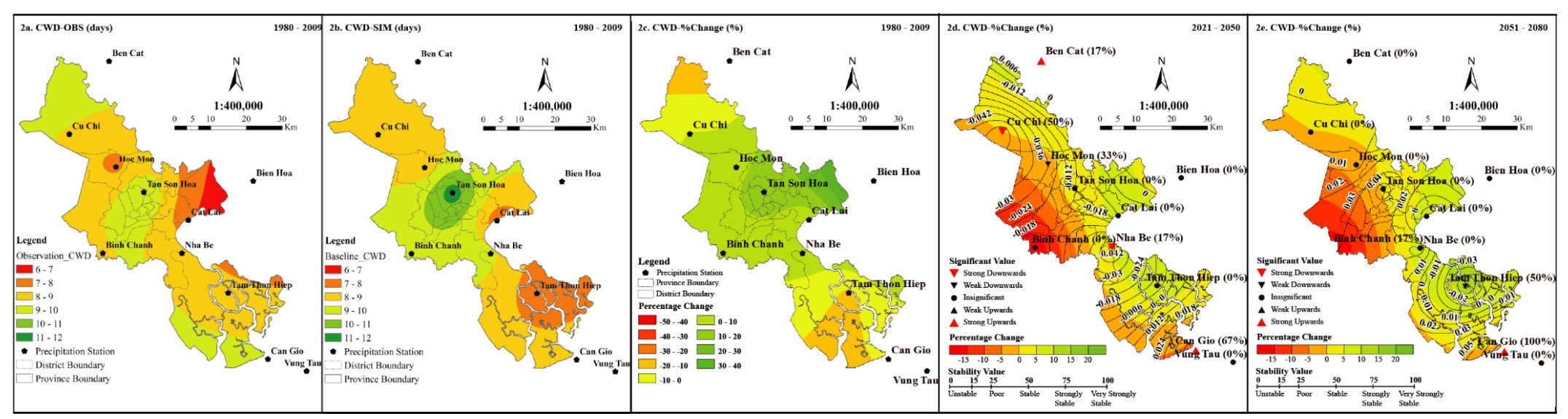

6.2 Spatial distribution of the observation (2a) and simulation (2b) extreme precipitation index (CWD) during the baseline period (1980-2009); relative differences between the simulation and observation (2c); relative changes between the near (2021-2050) and intermediate (2051-2080) future periods (2d,2e) with respect to the baseline.

Figure 6. Cont. 


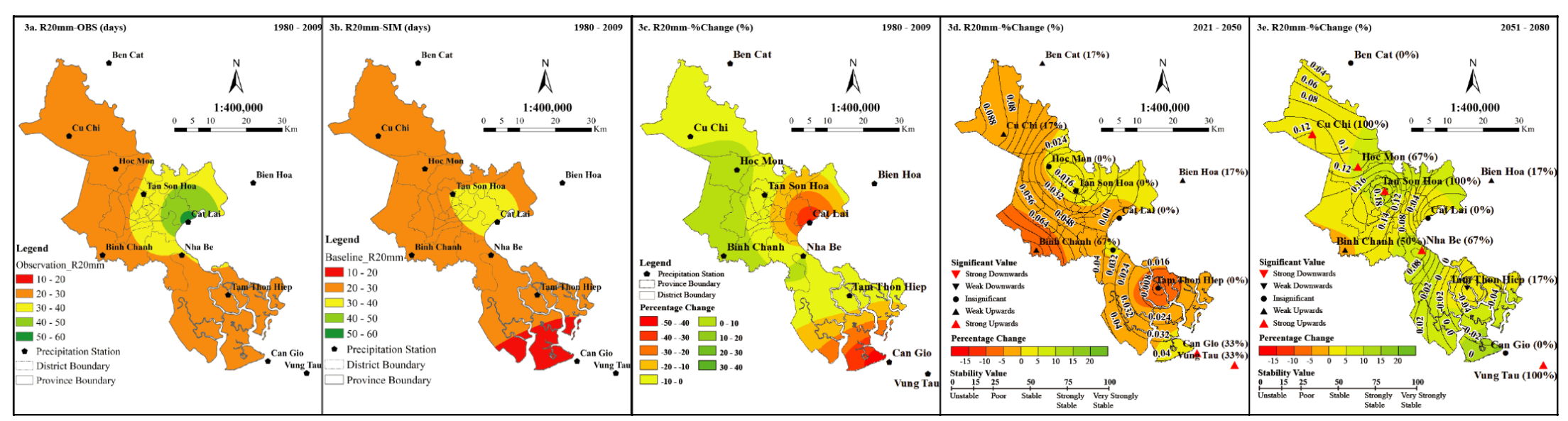

6.3. Spatial distribution of the observation (3a) and simulation ( $3 b$ ) extreme precipitation index (R20mm) during the baseline period (1980-2009); relative differences between the simulation and observation (3c); relative changes between the near (2021-2050) and intermediate (2051-2080) future periods (3d,3e) with respect to the baseline.

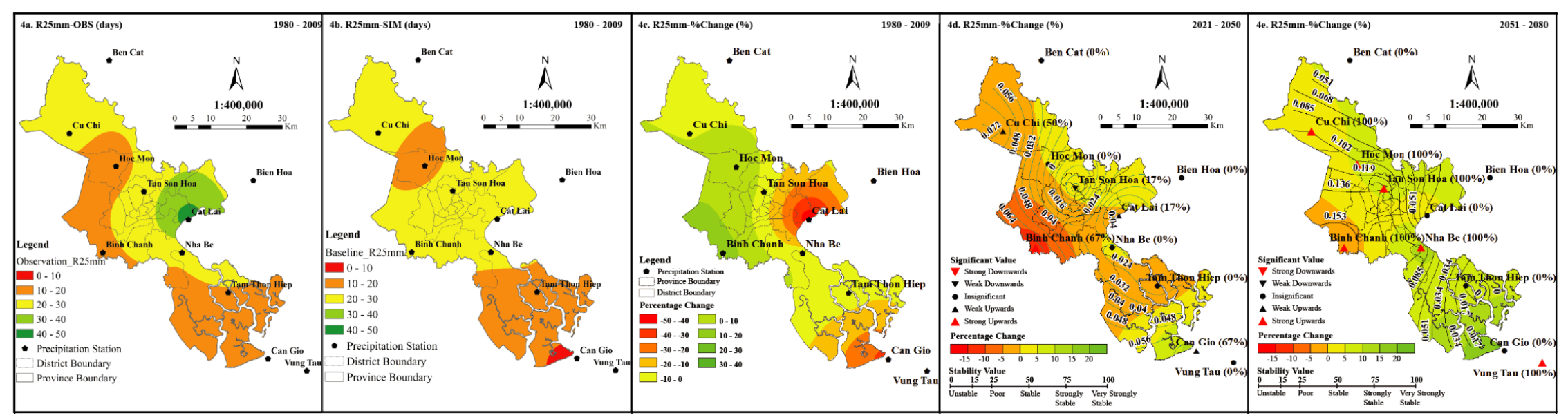

6.4. Spatial distribution of the observation (4a) and simulation (4b) extreme precipitation index (R25mm) during the baseline period (1980-2009); relative differences between the simulation and observation (4c); relative changes between the near (2021-2050) and intermediate (2051-2080) future periods (4d,4e) with respect to the baseline.

Figure 6. Cont. 


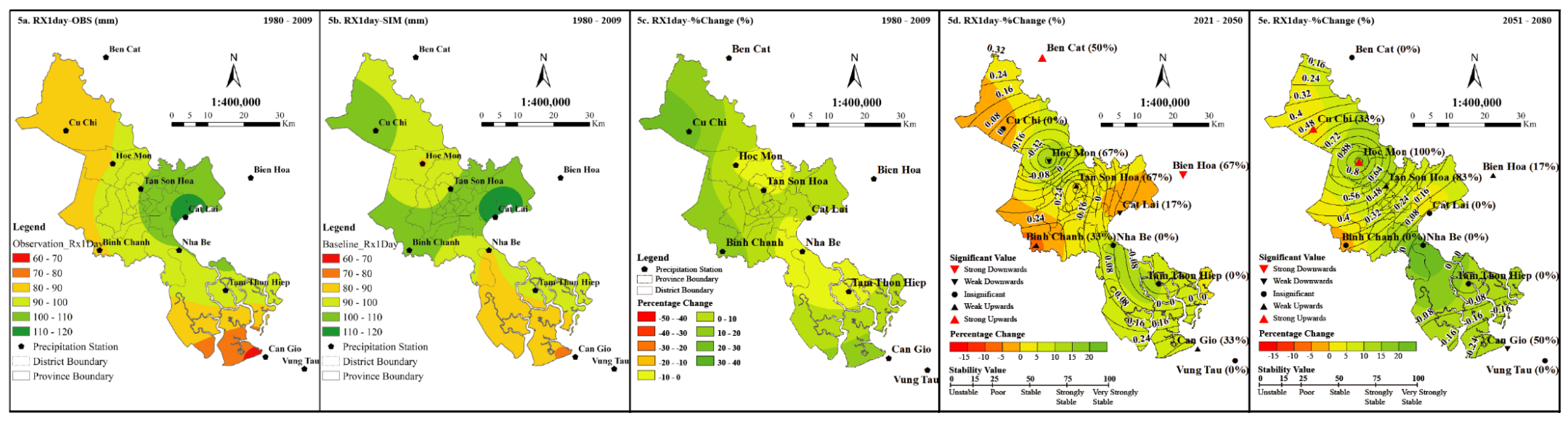

6.5. Spatial distribution of the observation (5a) and simulation (5b) extreme precipitation index (RX1day) during the baseline period (1980-2009); relative differences between the simulation and observation (5c); relative changes between the near (2021-2050) and intermediate (2051-2080) future periods (5d,5e) with respect to the baseline.

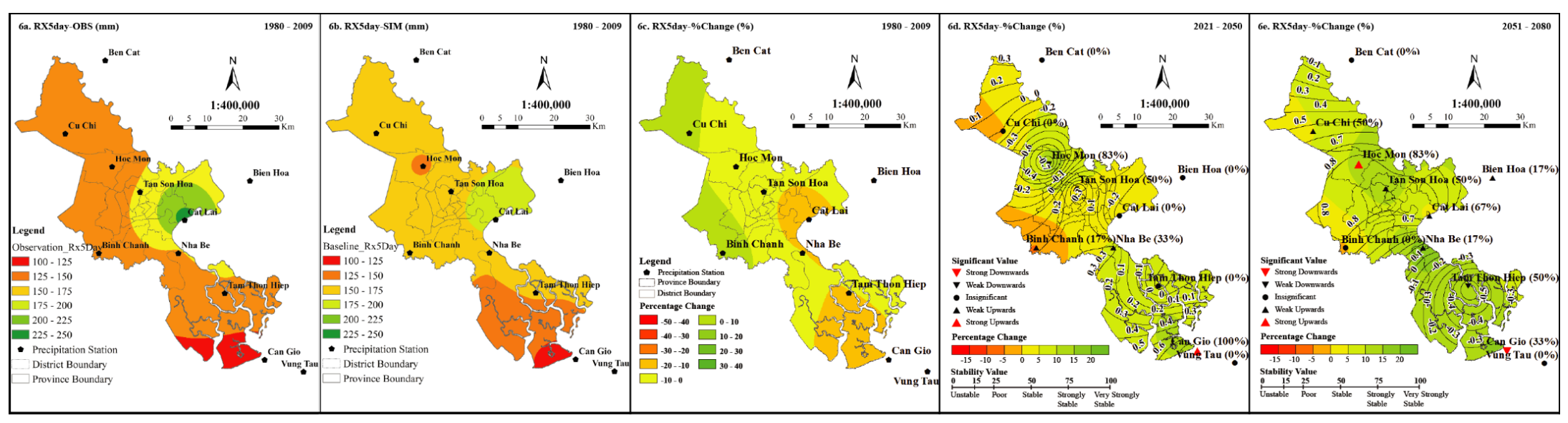

6.6. Spatial distribution of the observation (6a) and simulation (6b) extreme precipitation index (RX5day) during the baseline period (1980-2009); relative differences between the simulation and observation (6c); relative changes between the near (2021-2050) and intermediate (2051-2080) future periods (6d,6e) with respect to the baseline. 


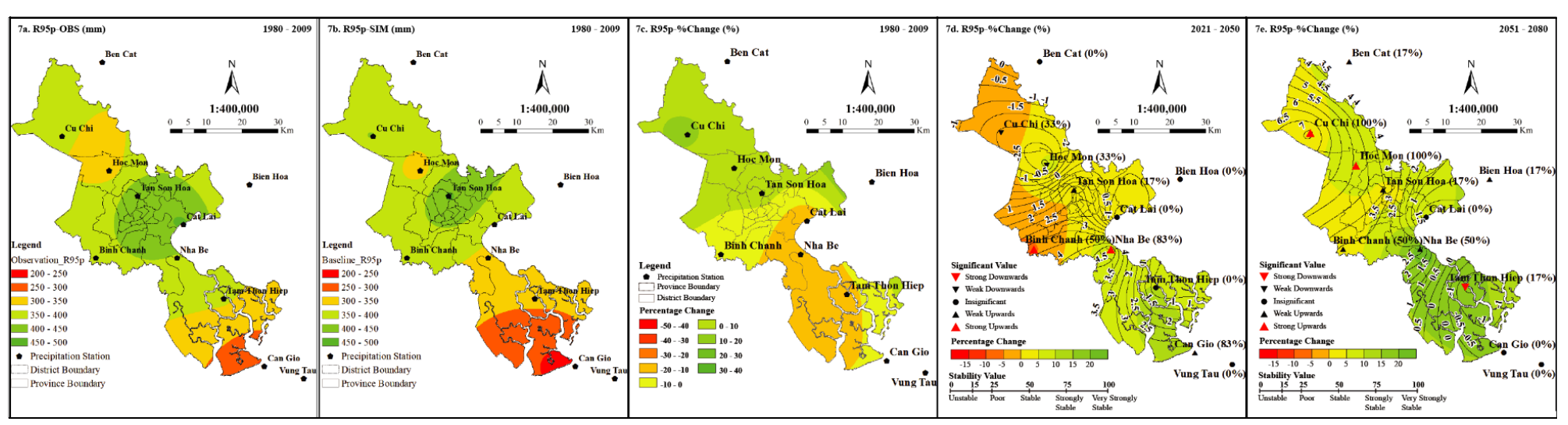

6.7. Spatial distribution of the observation (7a) and simulation (7b) extreme precipitation index (R95p) during the baseline period (1980-2009); relative differences between the simulation and observation (7c); relative changes between the near (2021-2050) and intermediate (2051-2080) future periods (7d,7e) with respect to the baseline period.

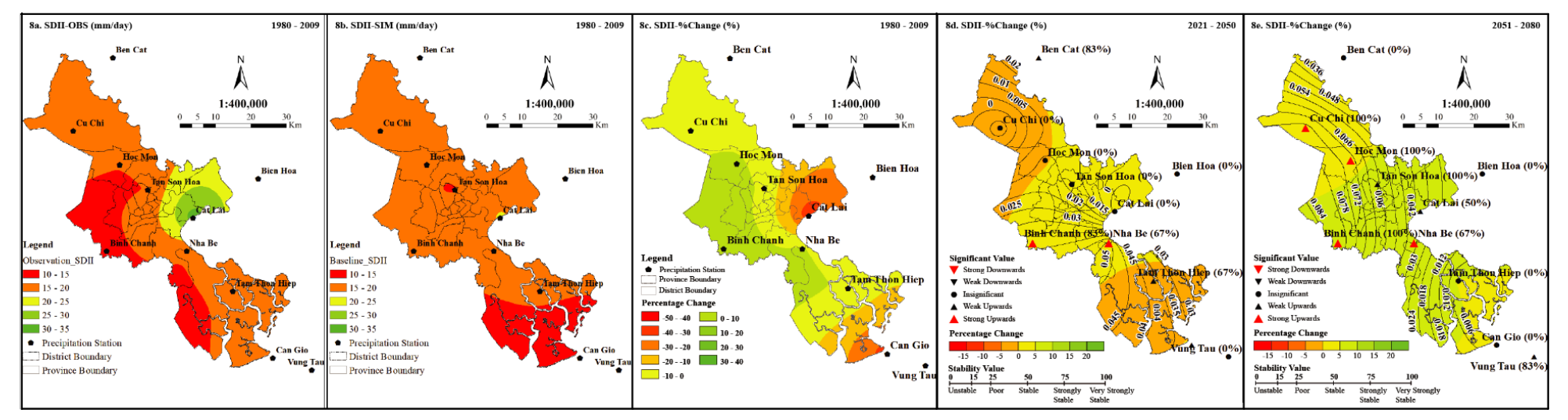

6.8. Spatial distribution of the observation (8a) and simulation (8b) extreme precipitation indices (SDII) during the baseline period (1980-2009); relative differences between the simulation and observation (8c); relative changes between the near (2021-2050) and intermediate (2051-2080) future periods (8d,8e) with respect to the baseline.

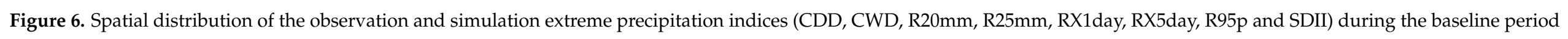

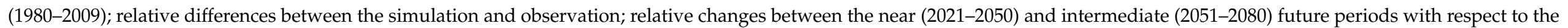

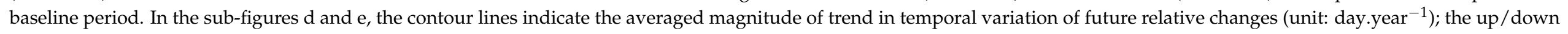

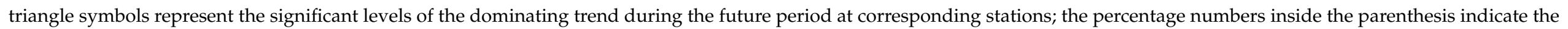
stability of trend at corresponding stations. 
In regard to the index CWD, the projected results shown in Figure 6(6.2) present the west-to-east increasing trend for the percentage of changes in extreme indices with respect to both future periods. Generally, the MME predicts few differences between the spatial distribution as well as the volume of relative change of the index CWD in both future periods. Particularly, in comparison with the historical period, the index CWD is predicted to be decreased from -18 to $-0.2 \%$, mainly in the central regions and small parts of other areas, while it is predicted to be increased from 0.9 to $11.4 \%$ mostly in the southern regions in both future periods. Additionally, the trend in changes of the projected index CWD shows statistically significant and stable tendency occurring at more stations in the near future period (2021-2050) than that in the later future period (2051-2080).

The spatial distribution of annual mean relative change in the indices $\mathrm{R} 20 \mathrm{~mm}$ and R25mm between the future and historical periods is shown in Figure 6(6.3,6.4). Generally, in comparison to the historical period, the MME predicts a decrease in both extreme indices in the near future period, while an increase in both indices is expected in the intermediate future period in most regions of the study area. Additionally, the projection results indicate that the future spatial distribution of percentage changes in the index R20 $\mathrm{mm}$ is comparable with that in the index R25mm. Particularly, in the near future period (2021-2050), the MME predicts a decrease in the index R20mm varying from $2.1 \%$ to $10.2 \%$, and in the index R25mm varying from $1.1 \%$ to $13 \%$ over most regions, especially in the central (Binh Chanh) and southern (Tam Thon Hiep) area. In comparison, an increase from 0.5 to $6 \%$ and 0.26 to $13.2 \%$ in the rest of this location is corresponding to the indices R20mm and R25mm, respectively (Figure 6(6.3d,6.4d)). For the same projection period, an increasing trend in the temporal changes of the indices' values is projected to be dominated at most stations with the average rates ranging from 0.4 to 0.9 [days.decade ${ }^{-1}$ ] for the index $\mathrm{R} 20 \mathrm{~mm}$, and from 0.1 to 0.7 [days.decade ${ }^{-1}$ ] for the index $\mathrm{R} 25 \mathrm{~mm}$. In the near future period, the stable and strongly upward trends are projected to mainly occur in the central and southern regions, while the downward trends are weak and unstable. In the intermediate future period (2051-2080), the MME predicts increasing from 0.5 to $17.3 \%$ for the index R20mm in most regions (with high values mostly distributed in the central and southern parts of the study area), while it presents a nuance with an increase ranging from 1.5 to $21.9 \%$ for the index $\mathrm{R} 25 \mathrm{~mm}$ in the similar spatial patterns. Additionally, during the intermediate future period, a slight decrease of $-1.6 \%$ and $-4.2 \%$ is projected to occur in a small part of the central area for R20mm and R25mm, respectively (Figure 6(6.3e,6.4e)). In this period, both extreme indices, $\mathrm{R} 20 \mathrm{~mm}$ and $\mathrm{R} 25 \mathrm{~mm}$, show strongly significant and stable increasing trends at most stations and equally distributed across the study area, in which the averaged magnitude of dominated trends is ranging from 0.5 to 2.1 , and from 1 to 1.6 [days.decade ${ }^{-1}$ ] for the indices, $\mathrm{R} 20 \mathrm{~mm}$ and $\mathrm{R} 25 \mathrm{~mm}$, respectively.

The relative changes in the maximum 1-day and 5-day total rainfall amount (RX1day and RX5day) between the future and the historical periods are shown in Figure $6(6.5 \mathrm{~d}, \mathrm{e}-6.6 \mathrm{~d}, \mathrm{e})$. The simulation results show that the spatial distribution of the indices RX1day and RX5day in each future period is relatively similar.

Generally, in the near future period (2021-2050), the multi-model ensemble predicts an average increase in RX1day from 3.5 to $14.4 \%$, and of RX5day from 0.2 to $12.5 \%$ in most regions, especially in the southern parts of the study area, while a decrease occurring in small parts of the central and northern regions is expected from -6.9 to $-1.1 \%$ and -5.4 to $-0.4 \%$ for the indices RX1day and RX5day, respectively. In this period, the statistically significant and stable increasing trends are dominated, and present high likelihood of occurrence in the central and southern parts of the study area, along with the averaged growing rates from (3.2-4.2) $\left[\mathrm{mm} /\right.$ decade $\left.^{-1}\right]$ and (1.8-8.5) $\left[\mathrm{mm}_{\text {.decade }}{ }^{-1}\right]$ for the indices RX1day and RX5day, respectively.

In the intermediate future period (2051-2080), the multi-model ensemble predicts an increase in both extreme indices RX1day and RX5day to be fluctuated across entire study area from 1.3 to $28.2 \%$ and 2.8 to $18.5 \%$, respectively; particularly, the highest values frequently concentrate in the southern regions. Besides, a slight decrease (less than $2.8 \%$ ) on 
average for both indices is also presented in the small parts of central regions. Additionally, the indices, RX1day and RX5day, are projected to demonstrate the statistically significant and stable upward trends in the northern and central regions, wherein an increasing rate of (0.8-10.1) [mm.decade ${ }^{-1}$ ] for the index RX1day, and of (2.1-9.1) [mm.decade ${ }^{-1}$ ] for the index RX5day; the stable and downward trends are predicted in the southern parts with a decreasing rate of $-3.5[\mathrm{~mm} \text {.decade }]^{-1}$ for the index RX1day and of $(-1.9$ to -7.0$)$ $\left[\mathrm{mm}\right.$. decade $\left.^{-1}\right]$ for the index RX5day.

Considering changes in the future intensity indices, the relative differences between the indices R95p and SDII in the future and historical period are shown in Figure $6(6.7 \mathrm{~d}, \mathrm{e}-6.8 \mathrm{~d}, \mathrm{e})$. In the period 2021-2050, the MME predicts a decrease in the index R95p from -4.3 to $-5.8 \%$ on average in some locations of the central and northern regions, and an increase from 0.01 to $12.5 \%$ in the rest of study area, especially in the southern regions (Figure 6(6.7d)). During the same period, the index R95p exhibits statistically significant and stable downward trend in the north of the study area with the averaged rates between -21.3 and -31.7 [days.decade ${ }^{-1}$ ], while the stable and significant upward trends are projected for the central and southern regions with the increasing rates varying from 21.1 to 33.5 [days.decade ${ }^{-1}$ ]. In the period 2051-2080, an average increase from 0.02 to $22.3 \%$ is forecasted by the MME over the entire study area, along with the northwestern-to-southeastern tendency of growth in the extreme indices (Figure 6(6.7e)). In this period, the statistically significant and stable trends are projected to be occurred in most regions. Moreover, in contrast to the near future period, the statistically strong and stable upwards (11.7 to 71.2 ) [days.decade ${ }^{-1}$ ] are projected with high likelihood of presence in the northern regions, while the statistically strong but poor-stability downward trends $(-7.6$ to -15.8$)$ [days.decade ${ }^{-1}$ ] are predicted to appear in the southern regions of the city during this intermediate future period.

The mean models predict a decrease in the index SDII from $-0.65 \%$ to $-3.77 \%$ on average in the north and south of the study area, while an increase from 0.1 to $4.8 \%$ is projected over entire central regions in the period 2021-2050 (Figure 6(6.8d)). During this period, SDII presents the domination of the statistically significant and stable increasing trends at most stations in the central (strong upwards) and southern regions (weak upwards), along with the averaged magnitude ranging from 0.1 to $0.4\left[\mathrm{~mm}_{\text {day }}{ }^{-1}\right.$.decade $\left.{ }^{-1}\right]$. In the period 2051-2080, the MME forecasts an increase from 2.8 to $9.1 \%$ on average over the entire study area, with high values being mainly observed in the central regions. During the same projection period, the statistically significant and stable upward trends are dominated at most stations over the study area (mainly distributed in the north and central regions) with the averaged magnitude of trends varying from 0.3 to $0.8\left[\mathrm{~mm} \cdot \mathrm{day}^{-1} \cdot \mathrm{decade}^{-1}\right]$ (Figure 6(6.8e)).

\section{Discussion}

The results of the current study on the spatiotemporal trend in changes of extreme precipitation indices between the future (2021-2080) and historical (1980-2009) periods indicate a general increase in most extreme indices over most regions in Ho Chi Minh City, especially in some parts of the southern and central areas. Currently, the studies on the impacts of climate change on extreme weather events in Vietnam are still limited in terms of quantity and quality of the research, especially studies using the extreme indices proposed by ETCCDI. Most of these studies were conducted for the entire Vietnam territory instead of focusing only on a specific location such as HCMC. To the best of our knowledge, our study seems to be the first reports assessing and mapping the changes of these extreme indices over HCMC for the future period in the context of climate change. The findings in our paper are consistent with previous remarkable related studies [58-60]. Particularly, our main results are in agreement with the report on Climate Change and Sea Level Rise Scenarios for Vietnam, which was a well-known and widely cited research work on this topic and published by the Ministry of Natural Resources and Environment of Vietnam [59], in which the authors only focused on the changes in RX1day and RX5day by the mid (2046- 
2065) and end (2080-2099) of 21st century with respect to the baseline period (1986-2005) under RCP4.5 and RCP8.5 scenarios. According to the report by MONRE, the RX1day and RX5day are expected to increase from 10 to $70 \%$ by the mid-century under RCP8.5 scenario; in which, the indices for HCMC area are projected to increase approximately between 10 and $30 \%$ with respect to the baseline period. In terms of the intensity extreme indices, our projection results agree with previous notable studies conducted by Ngo-Duc et al. [60] on applying regional climate models (RegCM4) with quantile mapping bias correction for evaluating extreme weather events over Southeast Asia regions for the midcentury period [60,61]. Here, the authors suggested an overall increase in CDD, CWD, SDII, R20mm, and R95p in the southern parts of Vietnam, especially in the rainy season. These results are reaffirmed by Tangang et al. [62] in their recent study on future changes in extreme precipitation indices under global warming of $2{ }^{\circ} \mathrm{C}$; in which, the significant and robust increasing changes in frequency and intensity indices are expected to occur in the mid-future period [59]. From these results, the central and southern regions of the city are warned to be threaten by flooding, while the plan of water management for rural areas in the northern sides should be prepared in order to address and mitigate the impact on agricultural sectors by potentially extreme droughts.

In this study, although the performance of the statistical downscaling tool and its incorporated GCMs was evaluated and confirmed to be able to reproduce and generate extreme precipitation indices, the model biases and uncertainties still remain in the projection results, especially in the projected spatial changes. Therefore, it is essential to apply proper bias correction methods, as well as more precise downscaling methods for maximizing the model performance. Moreover, for the approach of multi-model ensemble, the unweighted averaging multi-models used in this study are the simplest way but not effective when a better skillful model could be underestimated (or vice versa). Thereby, further research on individual model evaluation to create a weighted multi-model ensemble based on the ranked models could be a promising approach in order to optimize the simulation performance [63-65]. In addition, the relevant climate teleconnections (such as El Nino Southern Oscillation or Sea Surface Temperature) have a significant contribution to the behavior of climate extremes in the study area; therefore, their impacts on precipitation extremes should be taken into account in further research.

\section{Conclusions}

In this paper, the projected temporal and spatial changes in selected ETCCDI extreme precipitation indices between the future (2021-2080) and baseline period (1980-2009) in Ho Chi Minh City (Vietnam) were evaluated in the context of climate change. The projected extreme indices were computed based on daily rainfall data downscaled from five different GCMs under an RCP8.5 scenario using the LARS-WG tool. The performance of the LARSWG tool for the simulation of extreme precipitation indices has been examined using the model evaluation metrics, the Mann-Kendall statistical test and the Sen's estimator, which were also applied to analyze the significance, stability, and magnitude of trends in future changes. A summary of the major findings of this study is as follows:

- The LARS-WG tool has presented adequate performance for reproducing the extreme precipitation indices in most stations during the historical period (1980-2017), especially for simulating the spatial distribution of those indices. Notwithstanding, the uncertainty in simulation results was probably inevitable. Notably, the simulation tended to underestimate extreme indices in some parts of the central and southern regions, while overestimating these indices in the northern regions. In addition, the performance for simulating intensity indices is better than that for duration and frequency indices, especially for CWD and R20mm.

- In the historical period (1980-2017), the high values of temporally mean extreme indices were frequently observed in the central regions, while the low values of these indices were mainly distributed in the northern and southern regions. During this period, the decreasing trend in extreme indices were regularly observed at most 
stations in the study area. However, only $33 \%$ of this trend was significant and mainly distributed in the north and south parts of the study area.

- In the future periods, the projected extreme precipitation indices were computed from the downscaling from five different GCMs (EC-EARTH, HadGEM2-ES, GFDL-ESM2M, MIROC5, and MPI-ESM-MR) under the RCP8.5 emission scenario. Afterwards, the multi-model ensemble mean was calculated for evaluating the spatiotemporal changes in the near (2021-2050) and intermediate (2051-2080) future extreme indices with respect to the simulated indices in the baseline period (1980-2009). Generally, in comparison with the historical period, the temporally relative changes in most extreme precipitation indices are predicted to be increased during both future periods (2021-2080), but the index CDD. In which, the extreme intensity and frequency indices present a stronger magnitude and statistically significant increasing trends than those of extreme duration indices during the future periods. The spatial distribution of changes in future projected extreme indices across the study area is relatively systematic. In which, the highest values of mean absolute changes are frequently observed in the southern regions, while the lowest values of mean absolute changes are regularly observed in the northern and central areas of the study area in the future periods.

Moreover, the percentage changes in extreme indices in the intermediate future period (2051-2080) present noticeably higher values than those in the near future period (20212050) over most regions of the study area. In terms of relative changes in the same projection period, the multi-model ensemble reasonably predicts an increase in most extreme indices, and this mainly occurs in the southern regions. Meanwhile, a decrease in these indices is often projected in the northern and some parts in the central region of the study area. Furthermore, most stations obtain statistically insignificant and unstable trends in extreme precipitation indices during the near future period (2021-2050), but present statistically strong significance and high stability during the intermediate future period (2051-2080), especially in the central and southern parts of the study area.

Consequently, the prediction of increasing trends in extreme precipitation indices, especially for intensity and frequency of heavy and extreme heavy rainfall events, has posed the potential risk of more frequent floods in the central and southern regions of HCMC. Meanwhile, the projection shows a decrease in consecutive dry days in the northern areas, which implies the potential risk of severe droughts occurring in the northern regions of HCMC. Therefore, the simulation results in this paper could contribute a reasonable assessment and detailed potential-risk maps based on the changes in extreme precipitation indices across Ho Chi Minh City for the near and intermediate future periods in the 21st century. Although it is essential to reaffirm that these findings should be taken into consideration with caution due to the sources of uncertainty, such as the GCMs and statistical downscaling tool applied in this study, the achieved results could be recognized as the informative scientific references for the city governors to develop and implement comprehensive assessment, adaptation, and mitigation responding to the impact of extreme weather events in the context of climate change in Ho Chi Minh City.

Author Contributions: Conceptualization, D.N.K. and V.T.N.; data curation, N.T.Q. and P.T.T.N.; formal analysis, N.T.Q. and D.N.K.; funding acquisition, V.T.N.; investigation, N.T.Q. and P.T.T.N.; methodology, D.N.K. and N.T.Q.; software, N.T.Q. and P.T.T.N.; supervision, V.T.N. All authors have read and agreed to the published version of the manuscript.

Funding: The study was supported by the Department of Science and Technology of Ho Chi Minh City, managed by Institute for Computational Science and Technology under the funding number 05/2019/HĐ-KHCNTT.

Institutional Review Board Statement: Not applicable.

Informed Consent Statement: Not applicable.

Data Availability Statement: Not applicable. 
Acknowledgments: The study was supported by the Department of Science and Technology of Ho Chi Minh City, managed by Institute for Computational Science and Technology under the contract number 05/2019/HĐ-KHCNTT. The authors also would like to thank the anonymous reviewers for their valuable and constructive comments to improve our manuscript.

Conflicts of Interest: The authors declare no conflict of interest.

\section{References}

1. World Economic Forum. The Global Risks Report 2019, 14th ed.; The World Economic Forum: Geneva, Switzerland, 2019; ISBN 978-1-944835-15-6.

2. IPCC. Summary for Policymakers. In Intergovernmental Panel on Climate Change, editor. Clim Chang 2013-Phys Sci Basis [Internet]; Cambridge University Press: Cambridge, UK, 2013; pp. 1-30. Available online: https://www.cambridge.org/core/product/ identifier/CBO9781107415324A009/type/book_part (accessed on 5 October 2020).

3. IPCC. Summary for Policymakers. 2014. Available online: https://www.ipcc.ch/report/ar5/wg2/summary-for-policymakers (accessed on 5 October 2020).

4. Zhai, P.; Zhang, X.; Wan, H.; Pan, X. Trends in total precipitation and frequency of daily precipitation extremes over China. J. Clim. 2005, 18, 1096-1108. [CrossRef]

5. Bengtsson, L.; Rana, A. Long-term change of daily and multi-daily precipitation in southern Sweden. Hydrol. Process. 2014, 28, 2897-2911. [CrossRef]

6. Du, H.; Xia, J.; Zeng, S.; She, D.; Liu, J. Variations and statistical probability characteristic analysis of extreme precipitation events under climate change in Haihe River Basin, China. Hydrol. Process. 2014, 28, 913-925. [CrossRef]

7. Peñuelas, J.; Ciais, P.; Canadell, J.G.; Janssens, I.A.; Fernández-Martínez, M.; Carnicer, J.; Obersteiner, M.; Piao, S.; Vautard, R.; Sardans, J. Shifting from a fertilization-dominated to a warming-dominated period. Nat. Ecol. Evol. 2017, 1, 1438-1445. [CrossRef] [PubMed]

8. Hutchison, C.; Gravel, D.; Guichard, F.; Potvin, C. Effect of diversity on growth, mortality, and loss of resilience to extreme climate events in a tropical planted forest experiment. Sci. Rep. 2018, 8, 15443. [CrossRef] [PubMed]

9. Harrison, P.A.; Dunford, R.W.; Holman, I.P.; Cojocaru, G.; Madsen, M.S.; Chen, P.-Y.; Pedde, S.; Sandars, D. Differences between low-end and high-end climate change impacts in Europe across multiple sectors. Reg. Environ. Chang. 2019, 19, 695-709. [CrossRef]

10. Mishra, S.R.; Bhandari, P.M.; Issa, R.; Neupane, D.; Gurung, S.; Khanal, V. Climate change and adverse health events: Community perceptions from the Tanahu district of Nepal. Environ. Res. Lett. 2015, 10, 034007. [CrossRef]

11. Curtis, S.; Fair, A.; Wistow, J.; Val, D.V.; Oven, K. Impact of extreme weather events and climate change for health and social care systems. Environ. Health 2017, 16, 128. [CrossRef]

12. Rogelj, J.; Luderer, G.; Pietzcker, R.C.; Kriegler, E.; Schaeffer, M.; Krey, V.; Riahi, K. Energy system transformations for limiting end-of-century warming to below $1.5^{\circ} \mathrm{C}$. Nat. Clim. Chang. 2015, 5, 519-527. [CrossRef]

13. Bauer, N.; Mouratiadou, I.; Luderer, G.; Baumstark, L.; Brecha, R.J.; Edenhofer, O.; Kriegler, E. Global fossil energy markets and climate change mitigation-An analysis with REMIND. Clim. Chang. 2016, 136, 69-82. [CrossRef]

14. Carvajal, P.E.; Anandarajah, G.; Mulugetta, Y.; Dessens, O. Assessing uncertainty of climate change impacts on long-term hydropower generation using the CMIP5 ensemble-The case of Ecuador. Clim. Chang. 2017, 144, 611-624. [CrossRef]

15. Hassapoyannes, K. Mitigation Challenges and Options in Agriculture. In Global Challenges for Future Food and Agricultural Policies; Blandford, D., Hassapoyannes, K., Eds.; World Scientific: Singapore, 2019; pp. 249-266.

16. Hassapoyannes, K.; Blandford, D. Agriculture and Climate Change: National and International Policy Response. In Global Challenges for Future Food and Agricultural Policies; Blandford, D., Hassapoyannes, K., Eds.; World Scientific: Singapore, 2019; pp. 217-248.

17. Mendelsohn, R. Adapting to Climate Change in Agriculture: Challenges and Options. In Global Challenges for Future Food and Agricultural Policies; Blandford, D., Hassapoyannes, K., Eds.; World Scientific: Singapore, 2019; pp. $267-280$.

18. Halmstad, A.; Najafi, M.R.; Moradkhani, H. Analysis of precipitation extremes with the assessment of regional climate models over the Willamette River Basin, USA. Hydrol. Process. 2013, 27, 2579-2590. [CrossRef]

19. Rana, A.; Moradkhani, H. Spatial, temporal and frequency based climate change assessment in Columbia River Basin using multi downscaled-scenarios. Clim. Dyn. 2016, 47, 579-600. [CrossRef]

20. Rana, A.; Uvo, C.B.; Bengtsson, L.; Sarthi, P.P. Trend analysis for rainfall in Delhi and Mumbai, India. Clim. Dyn. 2012, 38, 45-56. [CrossRef]

21. ETCCDI Climate Change Indices. Available online: http://etccdi.pacificclimate.org/list_27_indices.shtml (accessed on 2 September 2018).

22. Karl, T.R.; Nicholls, N.; Ghazi, A. CLIVAR/GCOS/WMO Workshop on Indices and Indicators for Climate Extremes Workshop Summary. In Weather Clim Extrem; Springer: Dordrecht, The Netherlands, 1999; pp. 3-7. Available online: http://link.springer. com/10.1007/978-94-015-9265-9_2 (accessed on 15 September 2020).

23. Peterson, T.C.; Folland, C.C.; Gruza, G.; Hogg, W.; Mokssit, A.; Plummer, N. Report on the activities of the Working Group on Climate Change Detection and Related Rapporteurs 1998-2001; Springer: Southampton, UK, 2001; p. 144. 
24. Tian, Y.E.; Xu, Y.; Booij, M.J.; Zhang, Q.; Lin, S. Trends in precipitation extremes and long-term memory of runoff records in Zhejiang, east China. In IAHS Publication No. 344 (Hdro-climatology: Variability and Change); Franks, S.W., Boegh, E., Blyth, E., Hannah, D.M., Yilmaz, K.K., Eds.; IAHS Press: Wallingford, UK, 2011; pp. 227-232.

25. Wilby, R.L.; Dawson, C.W. SDSM 4.2-A Decision Support Tool for the Assessment of Regional Climate Change Impacts, Version 4.2 User Manual; Lancaster University, Lancaster/Environment Agency of England and Wales: Lancaster, UK, 2007; pp. 1-94.

26. Coupled Model Intercomparison Project Phase 5. Available online: https://pcmdi.llnl.gov/mips/cmip5/ (accessed on 20 August 2018).

27. ADB. Ho Chi Minh City Adaptation to Climate Change. 2010. Available online: https://www.adb.org/publications/ho-chiminh-city-adaptation-climate-change-summary-report (accessed on 25 September 2020).

28. Pillai, P.; Philips, B.R.; Shyamsundar, P.; Ahmed, K.; Wang, L. Climate Risks and Adaptation in Asian Coastal Megacities: A Synthesis report (English); World Bank Group: Washington, DC, USA, 2010.

29. KULP, S.A.; Strauss, B.H. New elevation data triple estimates of global vulnerability to sea-level rise and coastal flooding. Nat. Commun. 2019, 10, 4844. Available online: http://www.nature.com/articles/s41467-019-12808-z (accessed on 25 September 2020).

30. Storch, H.; Downes, N.; Thinh, N.-X.; Thamm, H.-P.; Phi, H.-L.; Thuc, T.; Thị Hiền Thuận, N.; Emberger, G.; Goedecke, M.; Welsch, J.; et al. Adaptation planning framework to climate change for the urban area of Ho Chi Minh City, Vietnam. In Proceedings of the Fifth Urban Research Symposium, 'Cities and Climate Change: Responding to an Urgent Agenda', Marseille, France, 28-30 June 2009.

31. Lupikasza, E. Spatial and temporal variability of extreme precipitation in Poland in the period 1951-2006. Int. J. Climatol. 2010, 30, 991-1007. [CrossRef]

32. Wu, C.; Huang, G.; Yu, H.; Chen, Z.; Ma, J. Spatial and temporal distributions of trends in climate extremes of the Feilaixia catchment in the upstream area of the Beijiang River Basin, South China. Int. J. Climatol. 2014, 34, 3161-3178. [CrossRef]

33. Shi, J.; Cui, L.; Wen, K.; Tian, Z.; Wei, P.; Zhang, B. Trends in the consecutive days of temperature and precipitation extremes in China during 1961-2015. Environ. Res. 2018, 161, 381-391. [CrossRef] [PubMed]

34. Thinh, N.X.; Bräuer, A.; Teucher, V. Introduction into work package urban flooding of the bmbf megacity research project TP. Ho Chi Minh. Environ. Inform. Ind. Environ. Prot. Concepts Methods Tools 2009, 2009, 223-232.

35. Van Leeuwen, C.J.; Dan, N.P.; Dieperink, C. The challenges of water governance in Ho Chi Minh City. Integr. Environ. Assess. Manag. 2016, 12, 345-352. [CrossRef]

36. ETCCDI Climate Change Indices. RClimdex and RHtests Toolkits. Available online: http:/ / etccdi.pacificclimate.org/software. shtml (accessed on 2 September 2018).

37. Alexander, L.V.; Zhang, X.; Peterson, T.C.; Caesar, J.; Gleason, B.; Klein Tank, A.M.G.; Haylock, M.; Collins, D.; Trewin, B.; Rahimzadeh, F.; et al. Global observed changes in daily climate extremes of temperature and precipitation. J. Geophys. Res. 2006, 111, D05109. [CrossRef]

38. Khoi, D.N.; Trang, H.T. Analysis of changes in precipitation and extremes events in Ho Chi Minh City, Vietnam. Procedia Eng. 2016, 142, 228-234. [CrossRef]

39. Mann, H.B. Nonparametric tests against trend. Econometrica 1945, 13, 245. Available online: https://www.jstor.org/stable/1907 187? origin=crossref (accessed on 11 October 2020). [CrossRef]

40. Kendall, M.G. Further contributions to the theory of paired comparisons. Biometrics 1955, 11, 43. Available online: https: //www.jstor.org/stable/3001479? origin=crossref (accessed on 11 October 2020). [CrossRef]

41. Sen, P.K. Robustness of some nonparametric procedures in linear models. Ann. Math. Stat. 1968, 39, 1913-1922. Available online: http:/ / projecteuclid.org/euclid.aoms/1177698021 (accessed on 11 October 2020). [CrossRef]

42. Zhang, Y.; Huang, G.; Wang, X.; Liu, Z. Observed changes in temperature extremes for the Beijing-Tianjin-Hebei region of China. Meteorol. Appl. 2017, 24, 74-83. [CrossRef]

43. von Storch, H. Misuses of Statistical Analysis in Climate Research. In Analysis of Climate Variability: Applications of Statistical Techniques; von Storch, H., Navarra, A., Eds.; Springer: Berlin/Heidelberg, Germany, 1999; pp. 11-26.

44. Gocic, M.; Trajkovic, S. Analysis of changes in meteorological variables using Mann-Kendall and Sen's slope estimator statistical tests in Serbia. Glob. Planet. Chang. 2013, 100, 172-182. Available online: http://linkinghub.elsevier.com/retrieve/pii/S092181811 2002032 (accessed on 11 October 2020). [CrossRef]

45. Hamed, K.H.; Rao, A.R. A modified Mann-Kendall trend test for autocorrelated data. J. Hydrol. 1998, 204, 182-196. [CrossRef]

46. Semenov, M.A.; Stratonovitch, P. Use of multi-model ensembles from global climate models for assessment of climate change impacts. Clim. Res. 2010, 41, 1-14. [CrossRef]

47. Bian, H.; Lü, H.; Sadeghi, A.M.; Zhu, Y.; Yu, Z.; Ouyang, F.; Su, J.; Chen, R. Assessment on the Effect of Climate Change on Streamflow in the Source Region of the Yangtze River, China. Water 2017, 9, 70.

48. Kumar, D.; Arya, D.S.; Murumkar, A.R.; Rahman, M.M. Impact of climate change on rainfall in Northwestern Bangladesh using multi-GCM ensembles. J. Climatol. 2014, 34, 1395-1404. [CrossRef]

49. King, L.M.M.; Irwin, S.; Sarwar, R.; McLeod, A.I.A.; Simonovic, S.P.P. The Effects of Climate Change on Extreme Precipitation Events in the Upper Thames River Basin: A Comparison of Downscaling Approaches. Can. Water Resour. J. Rev. Can. Ressour. Hydr. 2012, 37, 253-274. Available online: https:/ /www.tandfonline.com/doi/full/10.4296/cwrj2011-938 (accessed on 11 October 2020). [CrossRef] 
50. Lu, Y.; Qin, X.S.; Mandapaka, P.V. A combined weather generator and K-nearest-neighbour approach for assessing climate change impact on regional rainfall extremes. Int. J. Climatol. 2015, 35, 4493-4508. [CrossRef]

51. Khoi, D.N.; Sam, T.T.; Nhi, P.T.T.; Quan, N.T.; Hung, B.V.; Phung, N.K.; Van Thinh, N. Uncertainty assessment for climate change impact on streamflow and water quality in the dong nai river basin, vietnam. In World Environmental and Water Resources Congress; American Society of Civil Engineers: Reston, VA, USA, 2019; pp. 366-373. Available online: http://ascelibrary.org/doi/10.1061/ 9780784482346.037 (accessed on 11 October 2020).

52. Semenov, M.A. Simulation of extreme weather events by a stochastic weather generator. Clim. Res. 2008, 35, 203-212. [CrossRef]

53. Semenov, M.A.; Stratonovitch, P. Adapting wheat ideotypes for climate change: Accounting for uncertainties in CMIP5 climate projections. Clim. Res. 2015, 65, 123-139. [CrossRef]

54. Sam, T.T.; Khoi, D.N.; Thao, N.T.T.; Nhi, P.T.T.; Quan, N.T.; Hoan, N.X.; Nguyen, V.T. Impact of climate change on meteorological, hydrological and agricultural droughts in the Lower Mekong River Basin: A case study of the Srepok Basin, Vietnam. Water Environ. J. 2018. [CrossRef]

55. Willmott, C.J. On the validation of models. Phys. Geogr. 1981, 2, 184-194. [CrossRef]

56. Moriasi, D.N.; Gitau, M.W.; Pai, N.; Daggupati, P. Hydrologic and Water Quality Models: Performance Measures and Evaluation Criteria. Trans. ASABE 2015, 58, 1763-1785.

57. Legates, D.R.; McCabe, G.J. Evaluating the use of "goodness-of-fit" Measures in hydrologic and hydroclimatic model validation. Water Resour. Res. 1999, 35, 233-241. [CrossRef]

58. Hadi, S.J.; Tombul, M. Long-term spatiotemporal trend analysis of precipitation and temperature over Turkey. Meteorol. Appl. 2018, 25, 445-455. [CrossRef]

59. MONRE. Climate Change and Sea Level Rise Scenarios for Vietnam: Summary for Policymakers; Ministry of Natural Resources and Environment: Vietnam, Asia, 2016; p. 39.

60. Ngo-Duc, T.; Tangang, F.T.; Santisirisomboon, J.; Cruz, F.; Trinh-Tuan, L.; Nguyen-Xuan, T.; Phan-Van, T.; Juneng, L.; Narisma, G.; Singhruck, P.; et al. Performance evaluation of RegCM4 in simulating extreme rainfall and temperature indices over the CORDEX-Southeast Asia region. Int. J. Climatol. 2017, 37, 1634-1647. [CrossRef]

61. Trinh-Tuan, L.; Matsumoto, J.; Tangang, F.; Juneng, L.; Cruz, F.; Narisma, G.; Santisirisomboon, J.; Phan-Van, T.; Gunawan, D.; Aldrian, E.; et al. Application of quantile mapping bias correction for mid-future precipitation projections over Vietnam. SOLA 2019, 15, 1-6. [CrossRef]

62. Tangang, F.; Supari, S.; Chung, J.X.; Cruz, F.; Salimun, E.; Ngai, S.T.; Juneng, L.; Santisirisomboon, J.; Santisirisomboon, J.; Ngo-Duc, T; et al. Future changes in annual precipitation extremes over Southeast Asia under global warming of $2{ }^{\circ} \mathrm{C}$. APN Sci. Bull. 2018, 8, 3-8. [CrossRef]

63. Guo, D.; Zheng, F.; Gupta, H.; Maier, H.R. An inverse approach to perturb historical rainfall data for scenario-neutral climate impact studies. J. Hydrol. 2018, 556, 877-890. [CrossRef]

64. Jianga, C.; Xionga, L.; Wangb, D.; Liua, P.; Guoa, S.; Xua, C.Y. Separating the impacts of climate change and human activities on runoff using the Budyko-type equations with time-varying parameters. J. Hydrol. 2015, 522, 326-338. [CrossRef]

65. Kim, H.; David, W.; Marcouillerb, D.W.; Woosnam, K.M. Rescaling social dynamics in climate change: The implications of cumulative exposure, climate justice, and community resilience. Geoforum 2018, 96, 129-140. [CrossRef] 